\title{
Review Article \\ Targeting of the Tumor Necrosis Factor Receptor Superfamily for Cancer Immunotherapy
}

\author{
Edwin Bremer \\ Department of Surgery, Translational Surgical Oncology, University Medical Center Groningen, University of Groningen, \\ 9713GZ Groningen, The Netherlands
}

Correspondence should be addressed to Edwin Bremer; e.bremer@umcg.nl

Received 10 April 2013; Accepted 11 May 2013

Academic Editors: H. Al-Ali, J. Bentel, D. Canuti, L. Mutti, and R. V. Sionov

Copyright (C) 2013 Edwin Bremer. This is an open access article distributed under the Creative Commons Attribution License, which permits unrestricted use, distribution, and reproduction in any medium, provided the original work is properly cited.

The tumor necrosis factor (TNF) ligand and cognate TNF receptor superfamilies constitute an important regulatory axis that is pivotal for immune homeostasis and correct execution of immune responses. TNF ligands and receptors are involved in diverse biological processes ranging from the selective induction of cell death in potentially dangerous and superfluous cells to providing costimulatory signals that help mount an effective immune response. This diverse and important regulatory role in immunity has sparked great interest in the development of TNFL/TNFR-targeted cancer immunotherapeutics. In this review, I will discuss the biology of the most prominent proapoptotic and co-stimulatory TNF ligands and review their current status in cancer immunotherapy.

\section{Introduction}

The tumor necrosis factor (TNF) superfamily is comprised of 27 ligands that all share the hallmark extracellular TNF homology domain (THD) [1]. This THD triggers formation of non-covalent homotrimers. TNF ligands are typically expressed as type II transmembrane proteins, but in most ligands the extracellular domain can be subject to proteolytic processing into a soluble ligand. TNF ligands exert their biological function by binding to and activation of members of the TNF receptor (TNFR) superfamily. These TNFRs are typically expressed as trimeric type I transmembrane proteins and contain one to six cysteine-rich domains (CRDs) in their extracellular domain [2].

The TNF ligand superfamily has diverse functions in the immune system, one of which is the induction of apoptotic cell death in target cells. This function is performed by a family subgroup coined the Death Inducing Ligands, comprising the archetypal member TNF, FasL, and TRAIL. These Death Inducing Ligands bind to and activate cognate members of a TNFR subgroup termed the Death Receptors (DRs). DRs are characterized by the hallmark intracellular Death Domain (DD) that transmits the apoptotic signal. In general, ligand/receptor interaction induces formation of a Death Inducing Signaling Complex (DISC) to the cytoplasmic DD [3]. This DISC comprises the adaptor protein Fas-associated death domain (FADD) and an inactive proform of the cysteine protease procaspase- 8 . In addition to procaspase- 8 , the inhibitory caspase- 8 homologue cFLIP can be recruited to this complex [4]. Within the DISC, caspase- 8 is autoproteolytically processed via proximity-induced activation [5], whereupon a catalytic caspase-mediated pathway of apoptosis ensures execution of apoptotic cell death. All of these three proapoptotic TNF ligands hold considerable interest for tumoricidal cancer therapy [6].

A second important function of the TNF superfamily is the provision of co-stimulatory signals at distinct stages of an immune response [7]. Such co-stimulatory signaling is initiated upon TNFL/TNFR interaction and subsequent recruitment of members of the adaptor protein family of TNF receptor associated factor (TRAFs) [8]. The TRAF family consists of 6 members and is characterized by a highly conserved C-terminal domain that is responsible for trimer formation and interaction with the TNF receptors. The N-terminal domain is less conserved and is responsible 


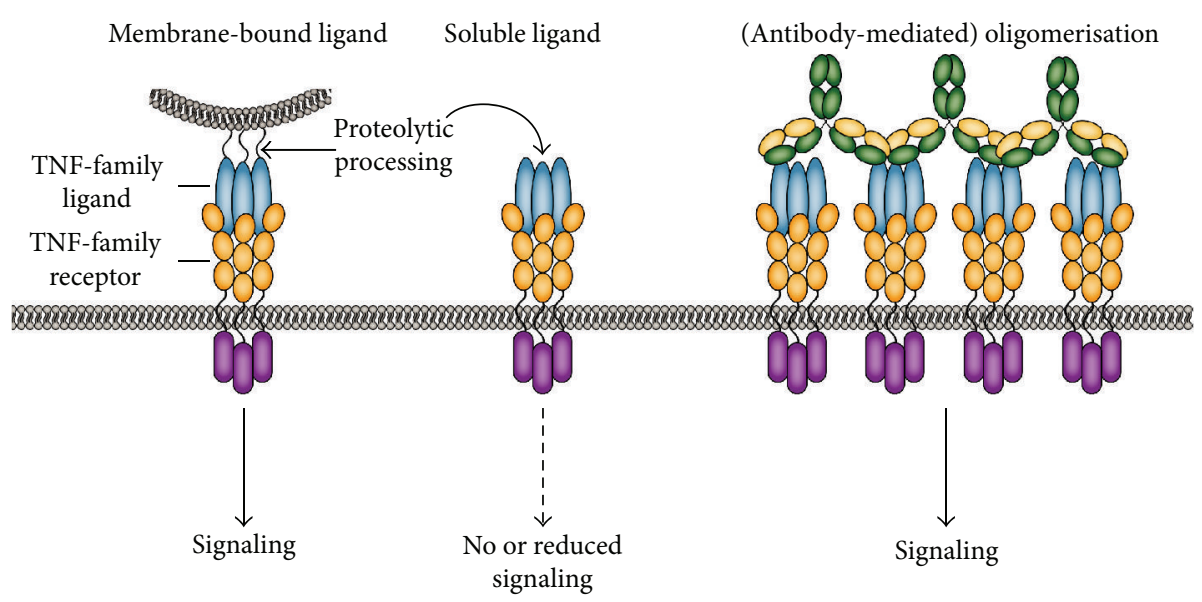

(a)

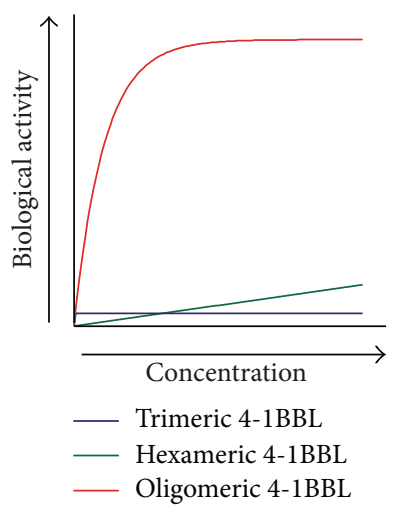

(b)

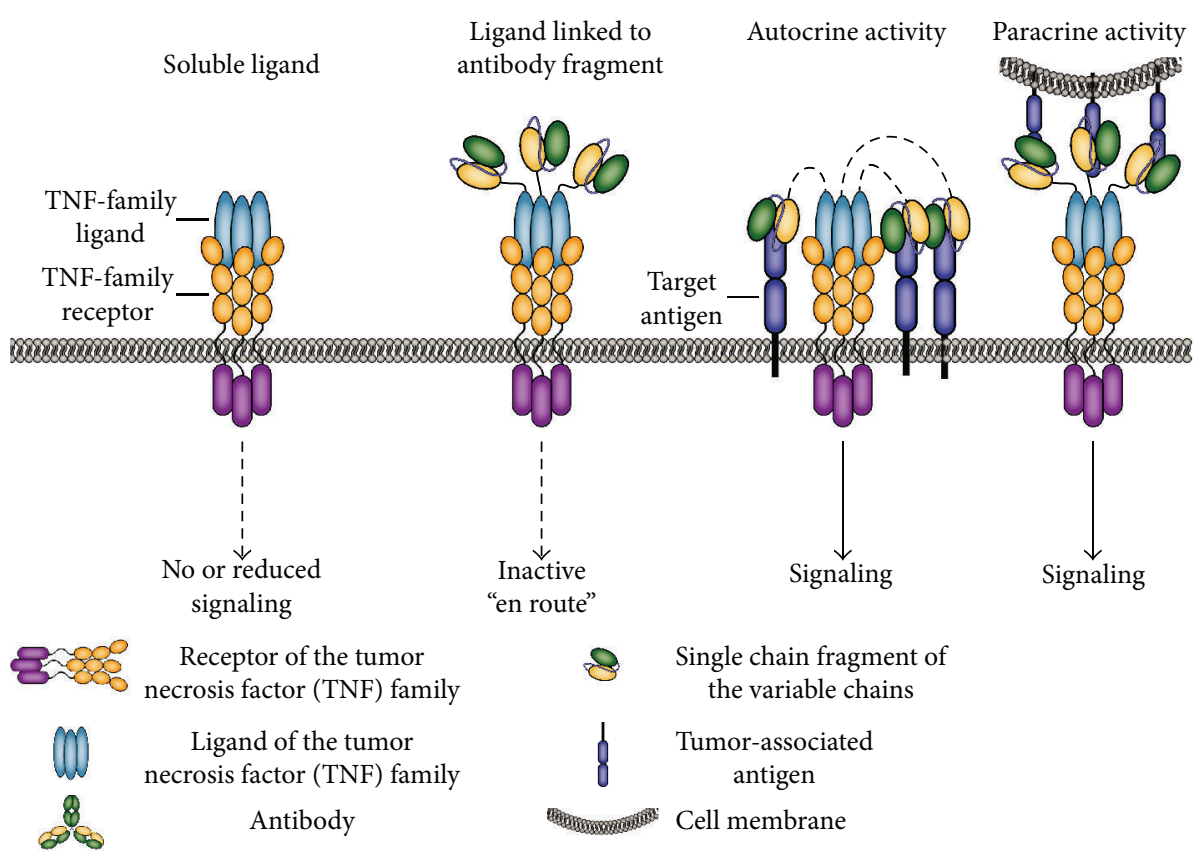

(c)

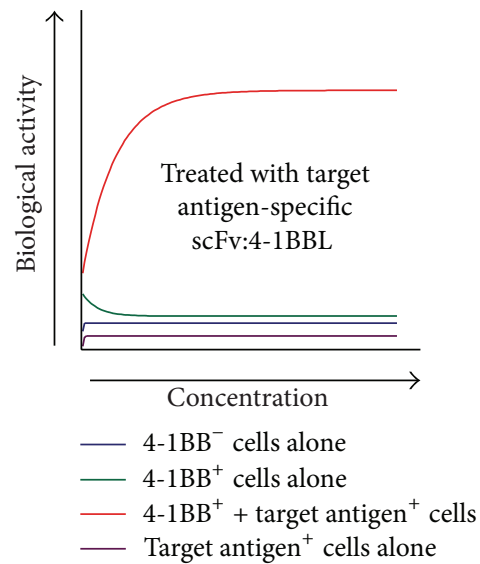

(d)

FIGURE 1: TNFL/TNFR signaling characteristics. (a) TNF-ligands are typically produced as type II transmembrane proteins, but the extracellular domain of most of these ligands can also be proteolytically cleaved by proteases, such as ADAM-17 (also known as TACE) [10], into a soluble form. Typically, the soluble ligand retains binding activity but has lost some or all receptor-activating activity. This activity can be restored by secondary cross-linking. (b) Signaling requirements of 4-1BB-signaling by s4-1BBL. (c) The cross-linking requirement of sTNF ligands makes their inclusion into an antibody fragment approach attractive. In brief, such a TNFL-fusion protein comprises a scFv antibody fragment genetically fused to the TNFL. This scFv:TNFL fusion protein is essentially inactive en route. However, upon target binding of the $\mathrm{scFv}$ antibody fragment domain the soluble ligand is converted into a signaling competent membrane-like ligand. (d). Illustration of target cell-restricted activation by scFv:4-1BBL.

for downstream proinflammatory and prosurvival signal transduction [9]. Typical signaling pathways activated by TRAFs are $\mathrm{NF} \kappa \mathrm{B}, \mathrm{PI} 3 \mathrm{~K}$, and $\mathrm{PKB}$. Various co-stimulatory TNFL/TNFR pairs, including CD40L/CD40, CD70/CD27, 4$1 \mathrm{BBL} / 4-1 \mathrm{BB}$, and $\mathrm{OX} 40 \mathrm{~L} / \mathrm{OX} 40$, have gained prominence as possible targets for cancer immunotherapy, in particular with the aim of induction or (re)activation of antitumor T-cell immunity.
As briefly mentioned earlier, a prominent feature of most TNF ligands is their proteolytic processing into soluble trimeric ligands (Figure 1(a)). Many of these soluble TNF ligands have a significantly reduced signaling activity compared to their transmembrane counterparts. Whereas the soluble trimeric ligand typically still binds the receptor, it requires secondary cross-linking to achieve TNFR activation reminiscent of its transmembrane TNF ligand counterpart 
as illustrated in Figure 1(b) for 4-1BBL. This feature of the TNF superfamily has formed the basis for their incorporation into antibody-based targeted therapies (see Figure 1(c)). In brief, a TNF ligand is genetically fused to a tumor specific antibody fragment, yielding a soluble targeted TNF ligand that is essentially inactive "en route." Upon antibody fragment binding to the target cells, this ligand is converted into a membrane-associated and fully signaling competent form of the TNF ligand as illustrated in Figure 1(d) for tumor targeted 4-1BBL.

In this review, I will first briefly describe the biology and then provide an overview of the state-of-the-art of therapeutic exploitation of the proapoptotic ligands TNF, FasL and TRAIL. Second, I will similarly review several prominent immune co-stimulatory TNF ligands, in particular CD40L, CD27L, 4-1BBL, and OX40L. For each of these ligands, I will further detail the rationale for their inclusion in antibodymediated targeting to achieve tumor-selective activity and reduced toxicity towards normal cells.

\section{Tumor Necrosis Factor (TNF)}

2.1. TNF Biology. TNF is the archetype superfamily member and is mainly produced not only by macrophages, but also by a broad variety of other cells, including lymphoid cells, mast cells, endothelial cells, fibroblasts, and neuronal tissue. TNF-alpha interacts with two receptors, namely TNF receptor 1 (TNFR1) and TNF receptor 2 (TNFR2). TNFR1 is constitutively expressed in most tissues and contains a cytoplasmic DD and as such is capable of transmitting TNFmediated proapoptotic signaling. TNFR2 lacks a cytoplasmic $\mathrm{DD}$ and is expressed predominantly on immune cells and endothelial cells.

Despite the fact that TNFR1 contains the hallmark DD required for induction of apoptosis, the main signaling outcome of TNF/TNFR1 interaction is not apoptotic cell death. Instead, TNF-induced TNFR1 signaling typically activates classical nuclear factor kappa $\mathrm{B}(\mathrm{NF} \kappa \mathrm{B})$ proinflammatory signaling [11]. In brief, binding of TNF to TNFR1 recruits the DD-containing adaptor molecules TRADD and RIP1. TNFR1-bound TRADD subsequently recruits TRAF2 and cIAP-1 and -2, whereupon NF $\mathrm{B}$ B as well as c-Jun $\mathrm{N}$-terminal kinase (JNK) signaling is induced $[12,13]$.

Upon receptor internalization this primary complex dissociates from TNFR1, after which a secondary complex comprising FADD, procaspase- 8 and cFLIP can be formed [11]. If cellular cIAP and cFLIP levels are limited, this secondary complex subsequently induces apoptosis via caspase8 . Notably, binding of membrane TNF to TNFR2 modulates TNFR1 signaling via proteasomal degradation of TRAF2 and cIAP. As a consequence, TNFR2 can tip the balance from inflammatory to apoptotic TNFR1 signaling (reviewed in [14]).

TNF is a major proinflammatory mediator of the innate immune system and can exert a large spectrum of bioactivities. Indeed, TNF modulates a host of (patho)physiological processes and is, for instance a critical mediator of shock and involved in both tissue regeneration/expansion and destruction [14]. As described earlier, the formation of the second signaling complex also enables TNF to trigger apoptotic cell death in certain circumstances. For instance, TNF proved to have potent tumoricidal activity in vitro and in mouse models in initial studies $[15,16]$, a finding that sparked interest in the development of TNF for cancer therapy.

\subsection{Triggering TNF/TNFR Signaling for Cancer Therapy. Like} most family members TNF is a transmembrane protein [17], but its extracellular domain can be proteolytically cleaved into a soluble form (sTNF) [10]. Of note, TNFR1-mediated downstream signaling is induced with similar efficacy by membrane TNF and sTNF (Figure 2(a)). In contrast, TNFR2 is poorly activated by sTNF and requires membrane TNF for efficient signaling [18]. In preclinical studies, recombinant sTNF displayed potent tumoricidal activity $[16,19]$. Unfortunately, systemic administration of recombinant sTNF only yielded minimal clinical activity in phase I clinical trials [20, 21] and was, moreover, associated with severe dose-limiting toxicity already at low doses. These initial findings clearly negated the use of sTNF as a systemic cancer therapeutic modality. Nevertheless, locoregional use of soluble TNF in combination with the chemotherapeutic drug melphalan yields impressive clinical responses in isolated limb and isolated liver perfusion [22, 23] and has become part of clinical practice. In these locoregional applications, sTNF is infused at over 50 times the maximal tolerated dose (MTD) as identified during systemic sTNF therapy. This high dose of TNF triggers endothelial cell apoptosis and subsequent destruction of the tumor vasculature, whereas normal blood vasculature is not affected. Consequently, tumor penetration of melphalan is enhanced.

Of note, the requirement for high concentrations of sTNF in isolated liver or limb perfusion indicates that in addition to TNFR1, TNFR2 signaling is required to sensitize tumor vasculature to apoptotic TNFR1 signaling. In this respect, the combined use of a low dose of sTNF with a TNFR2-selective TNF variant may optimize therapeutic effects on tumor vasculature and minimize toxicity. Of interest in this respect is a newly reported soluble TNFR2 agonist (TNC-scTNFR2), in which the trimerization domain of tenascin C (TNC) was fused to a TNFR2-selective single-chain TNF molecule comprised of three TNF domains connected by short peptide linkers (Figure 2(b)) [24]. TNC-scTNFR2 specifically activated TNFR2 and, importantly, possessed membrane-TNF like activity towards TNFR2.

2.3. Targeted TNF-Based Cancer Immunotherapy. The major TNF receptor, TNFR1, is ubiquitously expressed on normal cells, as a consequence of which soluble TNF has no or only limited tumor binding selectivity and considerable toxicity. Further, soluble TNF (sTNF) is practically incapable of triggering TNFR2 signaling and can only efficiently activate TNFR1, whereas TNFR2 signaling positively affects the efficacy of TNFR1 apoptotic signaling. All of these features clearly position TNF for inclusion in tumor targeting strategies, a strategy that has been pursued by various groups using scFv:TNF-based fusion proteins (Figure 2(b)). 


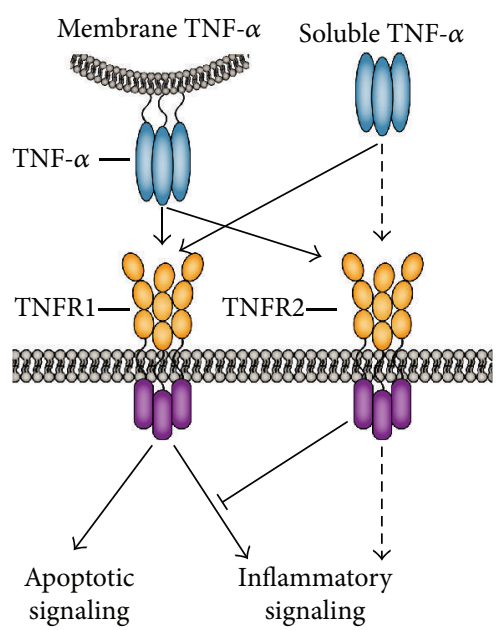

(a)

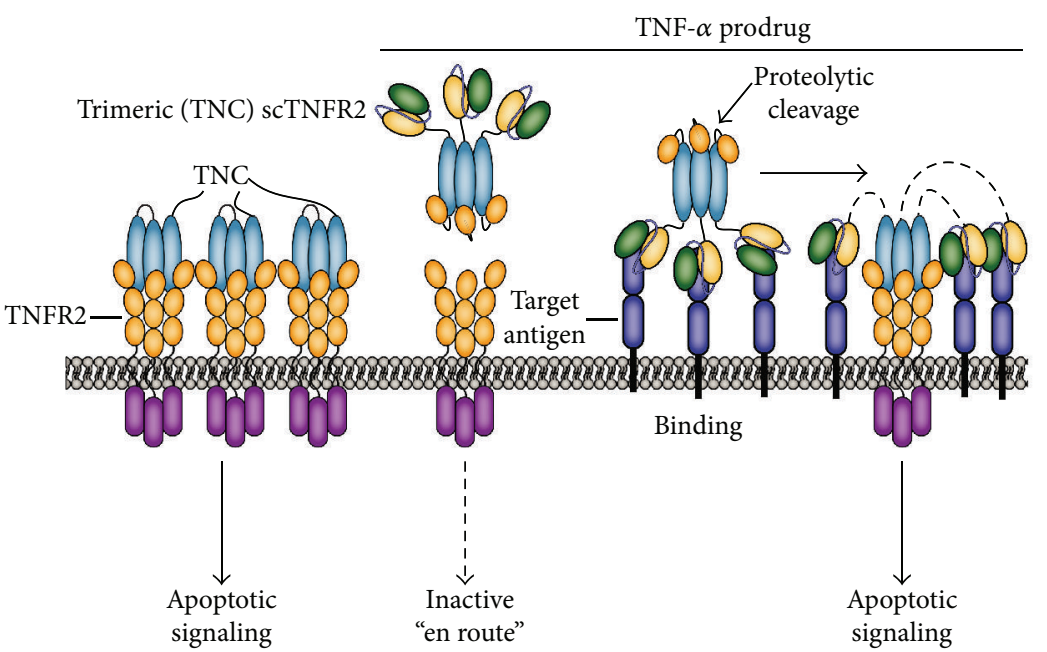

(b)

FIGURE 2: TNF/TNFR signaling and TNFR-targeted therapeutics. (a) TNFR1 and TNFR2 are effectively activated by membrane TNF, but sTNF can only trigger TNFR1-signaling. (b) TNFR-targeted drugs include a stabilized TNFR2-selective scTNF that may help to induce TNFR1 proapoptotic signaling, as well as targeted strategies such as scFv:sTNFL, and scFv:sTNF-TNFR1 prodrug constructs. The latter only become activated after target antigen-selective binding and subsequent cleavage of the TNFR1 inhibitory domain by tumor-overexpressed proteases.

Such scFv:TNF fusion protein will selectively bind to the corresponding target antigen via the antibody fragment. This high affinity interaction will ensure target cell accretion and, importantly, converts the sTNF domain into membranelike TNF. Consequently, target cell-bound scFv:TNF can efficiently activate TNFR2 and thereby sensitize cancer cells to induction of TNFR1 apoptotic signaling. Proof of concept for antibody-mediated delivery of sTNF has been generated for stromal (FAP), endothelial (integrins), and cellular targets (e.g., EGFR and Her2) (reviewed in [25]), with very favorable tumor-to-blood ratios 2-3 days after injection and potent tumoricidal activity at doses below the Maximum Tolerated Dose (MTD) of sTNF in preclinical models [2628]. Nevertheless, soluble TNF remains highly active towards TNFR1 expressed on normal cells in the scFv-TNF format. Further, target antigens used to deliver TNF in these scFvTNF fusion proteins are often not tumor specific but tumor associated or overexpressed, such as the Epidermal Growth Factor Receptor (EGFR) [29] or Her2 [30]. Consequently, ubiquitous TNFR1 activation or off-target activation of scFvTNF on normal target antigen-positive cells may occur upon infusion of scFv-TNF fusion proteins with the ensuing potential for toxicity such as those seen for sTNF [27, 31].

To further decrease the potential for toxicity issues, strategies that unleash the full tumoricidal potential of sTNF only at the intended site of action have been developed. Various recent advances have indeed made significant headway towards achieving such tumor-selective activation of sTNF. Firstly, sTNF was genetically fused to a fibroblast-activationprotein (FAP) specific antibody fragment that additionally contained the immunoglobulin dimerization domain [32, 33]. This dimerization domain ensured that the scFvFAP-TNF fusion protein formed relatively inactive dimers in solution, leading to a 10-20-fold reduction in bioactivity compared to
sTNF. However, upon FAP-selective binding the scFvFAPTNF fusion protein regained potent TNFR-mediated cytotoxicity. Alternatively, antibody fragment-TNF fusion proteins have been C-terminally fused with the ligand-binding domain of TNFR1. This TNFR1 domain binds and shields TNF "en route," yielding an inactive prodrug (Figure 2(b)). In this prodrug a special linker, designed to be sensitive to tumor-overexpressed proteases, was incorporated in between the TNF and TNFR1 domain. Consequently, the inhibitory TNFR1 fragment present in the prodrug will be cleaved by tumor overexpressed proteases and shed once at the site of the tumor. Proof of concept for this prodrug approach has been generated for the tumor stroma marker FAP with urokinase plasminogen activator $(\mathrm{uPa})$ and matrix metalloproteinase-2 (MMP2) mediated cleavage of the TNFR1 domain $[34,35]$.

\subsection{Perspectives for the Use of sTNF in Cancer Immunotherapy.} The potential for systemic application of sTNF in cancer patients critically depends on the tumor-selectivity of the recombinant sTNF-based drug. The above-described tumor-targeted antibody fragment-targeted TNF fusion proteins have these properties and should have a significantly improved toxicity profile while retaining potent tumoricidal activity. Thus, these targeting concepts generate hope for the applicability of this cytokine for systemic cancer therapy. However, it remains to be shown in in vivo follow-up studies that such more advanced strategies retain effectiveness and can be sufficiently cleaved and activated at the site of the tumor. In patients, this will to a great deal depend on the tumor microenvironmental concentration of active proteases, a characteristic that will have to be determined to identify patients likely to benefit from such therapeutics. Further, TNFR2 selective variants such as discussed earlier [24] offer the possibility of combining low dose sTNF and 
TNFR2 selective variants possibly in sequential treatment schedules to generate synergistic apoptotic antitumor activity with minimal side effects.

Of note, endogenous tumor-produced TNF can have a remarkable protumorigenic activity [19], for instance by inducing expression of interleukin 13 receptor alpha 2 (IL13R $\alpha 2$ ) on tumor resident monocytic cells and the subsequent production of the immunosuppressive cytokine TGF-beta [36]. Importantly, antagonistic antiTNF antibody treatment blocked IL13R $\alpha 2$ expression and restored active antitumor immune activity in colorectal, fibrosarcoma, and pancreatic murine models $[36,37]$. Thus, for recombinant sTNF derivatives the intratumoral TNFR cross-linking characteristics as well as intratumor concentration will be of critical importance to ensure tumoricidal activity in the absence of any low-dose and sub-optimal signaling mediated prosurvival signaling. Of note, blocking such prosurvival signaling may be a target for combinatorial design of TNFbased drugs with, for example, NFKB inhibitors, such as parthenolide, or clinical grade proteasome inhibitors such as bortezomib.

\section{Fas-Ligand (FasL)}

3.1. FasL Biology. FasL (also known as CD95L) is a type II transmembrane protein expressed on immune effector cell such as T-cells. The main receptor for the ligand of FasL is the type I transmembrane receptor Fas (CD95) [38, 39], which is expressed on a variety of normal human cells as a homotrimer [40-42]. Binding of FasL to Fas triggers oligomerization of Fas and initiates apoptotic signaling by DISC formation at the intracellular DD [3]. Of note, nonapoptotic NF $\kappa$ Bmediated proinflammatory signaling can also be induced by FasL $[43,44]$, although this signal is usually overruled by the apoptotic signaling pathway. However, in cells with high endogenous levels of apoptosis inhibitors, such as Bcl2 or Bcl-xL-expressing cells, NF $\kappa$ B-signaling by Fas can dominate. FasL can further interact with decoy receptor 3 (DcR3) [45], a soluble receptor that competitively inhibits FasL/Fas-mediated signaling. Indeed, high circulating levels of DcR3 have been shown to protect against FasL signaling in autoimmunity, for instance, by protection of synovial fibroblasts in rheumatoid arthritis [46].

Next to the granzyme/perforin cytolytic pathway, the FasL/Fas system represents a major cytolytic effector route of CD8+ T-cells pivotal for elimination of target cells [47, 48]. Further, Fas-apoptotic signaling is also crucial for the reciprocal elimination of activated $\mathrm{T}$ cells during the resolution phase of a T-cell immune response $[49,50]$. Of note, like most TNF ligands the extracellular domain of transmembrane FasL is subject to proteolytic cleavage, which generates soluble homotrimeric FasL (sFasL). Elevated serum levels of sFasL have been documented in pathological conditions among others in lymphoma patients [51] and synovial fluid of rheumatoid arthritis patients [52]. Importantly, processed sFasL is approximately 1000 -fold less effective in inducing Fas signaling than transmembrane FasL (Figure 3(a)) [53,
54]. Thus, endogenous sFasL likely competitively inhibits the activity of immune effector cell-expressed full length FasL.

3.2. Triggering FasL/Fas Signaling for Cancer Therapy. The prominent role of FasL/Fas signaling as cytolytic pathway in T-cell immunity sparked great interest in its use in cancer therapy. Indeed, agonistic human antiFas antibody triggered potent cytotoxicity in human xenografted tumors in murine models [38]. Unfortunately, upon further evaluation of Fas-based therapy in syngeneic murine tumor models and murine Fas-specific antibodies it became apparent that ubiquitous Fas activation is associated with severe lethal hepatotoxicity within $6 \mathrm{~h}$ of injection [55]. These early findings negated the systemic use of Fas agonists for cancer therapy. Nevertheless, compartmentalized activation of Fas signaling proved to be effective in murine models without serious adverse toxicity. For instance, intraperitoneal administration of sFasL efficiently eliminated murine lymphoma cells in the absence of toxicity [56]. Together, these data indicate that compartmentalized use of ubiquitous Fas-agonists or the design of more target-selective agonists holds considerable therapeutic potential.

In recent years, efforts have focused on the design of such more selective tumoricidal Fas agonists. As described earlier homotrimeric sFasL is inactive/poorly active even at very high concentrations. However, hexameric recombinant forms of sFasL, such as Fc-FasL or mega-FasL, were fully capable of activating Fas-apoptotic signaling in malignant hematopoietic cells while retaining an acceptable toxicity profile in mice (Figure 3(a)) [57, 58]. More recently, a polymeric dodecamer FasL chimera was described in which FasL was fused to the homotypic aggregation domain of Leukemia Inhibitory Factor receptor gp1909. This multimeric FasL chimera also proved highly active in vitro, possessed tumoricidal activity in vivo, and had no liver toxicity at tumoricidal concentrations [59]. Thus, it is possible to design sFasL variants that possess a clear therapeutic window, at least in murine model systems.

3.3. Targeted FasL-Based Cancer Immunotherapy. As described above, homotrimeric sFasL is inactive but can be reactivated by virtue of oligomerization. Similarly, immobilization of sFasL on extracellular matrix components restored membrane FasL-like apoptotic activity [60]. These characteristics establish sFasL as a prime target for inclusion in antibody-targeted scFv-based therapy (Figure 3(b)). In an scFv:sFasL-based fusion protein the antibody fragment will ensure high affinity and selective binding to the predefined target. Consequently, the inactive sFasL domain is converted into a membrane-like FasL that can activate Fas-apoptotic signaling. Proof of concept for this strategy was obtained for several target antigens, including the tumor stroma marker FAP [61], the T-cell surface markers CD7 [62], and the Bcell surface marker CD20 [63]. Specifically, FAP-selective binding to FAP-positive HT1080 cells induced Fas apoptotic signaling at a 1000-fold lower ED50 compared to corresponding parental FAP-negative HT1080 cells [61]. Further, CD7-specific binding of scFvCD7:sFasL triggered apoptotic 


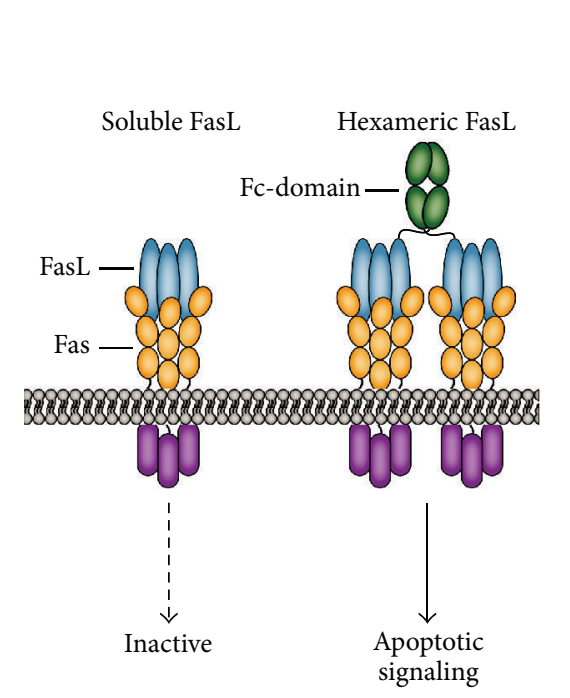

(a)

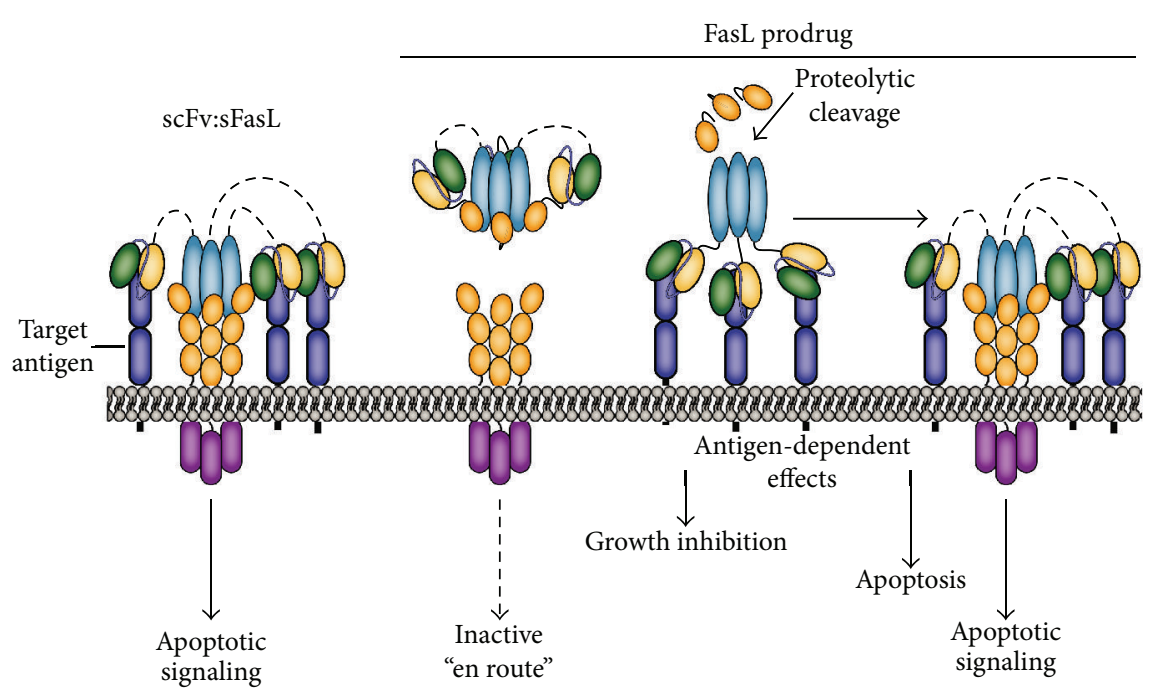

(b)

FIgURE 3: Design of FasL/Fas-based cancer therapeutics. (a) Soluble homotrimeric FasL is essentially incapable of activating Fas-apoptotic signaling. However, hexamerized recombinant forms of sFasL have Fas-activating capacity analogous to membrane-expressed FasL. (b) The inactivity of homotrimeric sFasL has been exploited in scFv:FasL fusion proteins, by which the full apoptotic potential of FasL/Fas signaling is unleashed only upon target antigen-selective binding. To further increase the safety of FasL-based therapeutics, a FasL-based prodrug strategy analogous to TNF has been designed and evaluated.

elimination of CD7-positive T-cell leukemic cells but lacked activity on CD7-negative cells [62]. Of note, scFvCD7:FasL proved inactive towards normal CD7-positive cells, including resting T-cell and NK-cells. In contrast, activated T-cells were sensitive to apoptotic elimination by scFvCD7:FasL, probably due to the intrinsic increase in sensitivity to AICD occurring in T-cells at later activation stages. In actual fact, this T-cell restricted activity profile also enabled the selective elimination of pathogenic synovial fluid T-cells [64].

Interestingly, inclusion of a rituximab-derived antiCD20 antibody fragment in an scFv:sFasL fusion protein revealed a dual tumoricidal activity [63]. In brief, CD20-selective binding of scFvRit:sFasL induced CD20-apoptotic signaling, a finding corresponding with published reports that rituximab can activate apoptosis by cross-linking of CD20 [65]. Second, CD20-immobilized scFvRit:sFasL efficiently triggered Fasapoptotic signaling. Of note, dual treatment of malignant B-cells with rituximab and agonistic antiFas antibody also triggers synergistic apoptotic cell death $[66,67]$. However, in a side-by-side comparison scFvRit:sFasL proved superior to cotreatment with rituximab and sFasL or antiFas antibody.

\subsection{Perspectives for FasL/Fas-Based Cancer Immunotherapy.} To therapeutically exploit Fas-apoptotic signalling it is imperative to prevent ubiquitous activation of this receptor, particularly in the liver. The use of homotrimeric scFv:sFasL fusion proteins appear to fulfil this requirement, with as $>1000$-fold increase in agonistic activity upon target antigen-selective binding. However, the safety of this strategy still depends on the expression pattern of the targeted antigen. Indeed, most established target antigens in antibody-based therapy are not tumor specific but tumor associated and tumoroverexpressed. To further maximize tumor-restricted activation a pretargeting approach may be developed. For instance, sFasL can be fused to a fluorescein- (FITC)-specific scFv. Cancer lesions can be first targeted using an FITC-labelled antitumor antibody. Once the optimal tumor-to-tissue ratio has been achieved for this antibody, scFv-FITC:sFasL can be infused to enable FITC-specific and cancer lesion restricted accretion of scFv-FITC:sFasL. An analogous approach has been used for the selective elimination of Fas-scFv-FITC transduced cells as a conditional death switch [68].

Alternatively, a prodrug scFv:FasL-based strategy analogous to that reported for scFv:TNF has been pursued to ensure tumor-restricted FasL-induced signaling [69]. In this case, the receptor Fas and a TNC trimerization domain was $\mathrm{N}$-terminally fused via a protease sensitive linker to the scFv:FasL construct. In this prodrug format, scFv:FasL fusion remained inactive en route. However, upon target antigen binding, tumor-overexpressed proteases cleaved the inhibitory Fas fragment, whereby FasL-apoptotic signalling was unmasked. Proof of concept in vitro as well as in vivo for such tumor selective activation was reported for the stromal marker FAP and the proteases UPA and MMP2 [69].

\section{TNF-Related Apoptosis Inducing Ligand (TRAIL)}

4.1. TRAIL Biology. TRAIL is expressed on various immune effector cells and binds to 4 surface receptors of the TNFR superfamily, TRAIL-R1 (DR4), TRAIL-R2 (DR5), TRAIL-R3 (DcR1), and TRAIL-R4 (DcR2) (reviewed in [70]). Of these four, TRAIL-R1 and TRAIL-R2 contain the characteristic 
DD required for induction of apoptosis. TRAIL-R3 is a phospholipid-anchored receptor, whereas TRAIL-R4 contains a truncated intracellular domain. Consequently, neither TRAIL-R3 nor TRAIL-R4 are capable of apoptotic signaling and are thought to have a decoy function. Of note, evidence for formation of heteromeric TRAIL-receptors comprised of TRAIL-R2 and TRAIL-R4 highlights an added layer of complexity to TRAIL/TRAIL-receptor mediated signaling that is yet to be fully elucidated $[71,72]$. TRAIL can further bind to osteoprotegerin, whereby it may regulate vascular biology [73] and bone turnover [74].

TRAIL is an effector molecule involved in antiviral and antitumor immune responses, particularly in tumor immune surveillance by liver NK-cells, as $\mathrm{TRAIL}^{-/-}$mice develop increased liver metastases [75]. Expression of TRAIL is induced by interferons on CD4+ and CD8+ T-cells [76], in virally infected cells [77], and on multiple myeloma cells [78]. Further, TRAIL was shown to be required for graft versus tumor activity upon allogeneic hematopoietic stem cell transplantation [79].

Apoptotic signaling by TRAIL via TRAIL-R1/-2 is similar to Fas-induced apoptotic signaling, with formation of the DISC, processing of caspase-8, and subsequent downstream caspase-mediated apoptotic signaling. Of note, in the presence of high levels of endogenous apoptosis inhibitors, such as cFLIP, TRAIL can also trigger proinflammatory NF $\kappa \mathrm{B}-$ signaling. Such proinflammatory signaling can actually promote tumorigenicity, as evidenced by a pancreatic cancer model in which treatment with TRAIL promoted metastasis formation of xenografted TRAIL-resistant pancreatic cancer cells $[80]$.

4.2. Triggering TRAIL/TRAIL-Receptor Signaling for Cancer Therapy. TRAIL/TRAIL-receptor agonists have shown prominent tumoricidal activity in a host of preclinical studies and in a variety of tumor types, whereas no or limited activity was detected towards normal human cells [81]. Based on this promising activity profile, a recombinant trimeric form of TRAIL, named dulanermin, entered phase I/II clinical trials with no apparent toxicity (reviewed in [82]). Dulanermin is further being explored in a multicenter clinical trail, with preliminary results indicating a number of partial responses and stable disease at higher doses of $8 \mathrm{mg} / \mathrm{kg}[81,83]$. In addition, combination of dulanermin with antiCD20 antibody rituximab yielded 2 complete and 1 partial response in nonHodgkin lymphoma patients $[83,84]$, which corresponds to the reported preclinical synergic activity of rituximab and TRAILR agonists $[85,86]$. Unfortunately, a recent phase II trial in non small cell lung cancer patients revealed no added benefit of combined Dulanermin and chemotherapy treatment [87].

At the same time, a number of TRAIL-R1 and TRAIL-R2 specific agonistic antibodies have entered clinical evaluation, typically with low to absent toxicity but also without strong clinical benefit as single agent (reviewed in [88]). Thus, clinical experience with both TRAIL and agonistic TRAILR antibodies indicate that real clinical benefit will most likely require combinatorial therapy. Most ongoing clinical trials indeed evaluate combination therapy of TRAILR agonists with, for example, chemotherapy or targeted therapeutics such as the CD20-antibody rituximab as referred to earlier. Such combinatorial approaches may also help to overcome the potential issue of intrinsic resistance to TRAIL, as for instance observed in $\sim 50 \%$ of tumor cell lines in vitro. In addition, combinatorial treatment strategies may prevent the development of acquired resistance to TRAILR agonists. The potential for acquiring resistance to TRAILR agonists was demonstrated preclinically upon treatment of cancer cells with suboptimal concentrations of an antiTRAIL-R2 antibody. Subsequent repeat treatment with therapeutic concentrations of the same antibody proved ineffective, whereas TRAIL and antiTRAIL-R1 still triggered cell death [89]. From the above it is clear that clinical implementation of TRAILR agonists will most likely be in the context of combinatorial strategies that are specifically designed to trigger synergistic tumoricidal activity.

4.3. Targeted TRAIL-Based Cancer Immunotherapy. The signaling characteristics of the TRAIL/TRAIL-receptor system are such that sTRAIL appears well suited for use in antibody fragment-targeted therapy. In particular, whereas sTRAIL has retained receptor activating potential for TRAIL-R1, it cannot efficiently activate TRAIL-R2 signaling (Figure 4(a)) [90]. Indeed, TRAIL-R2 activation by TRAIL is reminiscent of Fas activation by sFasL in that it requires oligomerization to be effectuated. Further TRAIL receptors are ubiquitously expressed in the human body, which will limit tumor accretion of sTRAIL. Tumor accretion will further be limited by the very short half-life of sTRAIL $\sim 30 \mathrm{~min}$ in cynamolgus monkeys, a value which closely corresponded to the half-life identified in patients in a phase I clinical trial [81, 91].

Fusing sTRAIL to a targeting domain, such as a $s c F v$ antibody fragment, will yield a fusion protein with various advantageous properties (Figure 4(b)). First, by virtue of the homotrimerization of sTRAIL, a scFv:TRAIL fusion protein will have an approximate molecular weight of $180 \mathrm{KDa}$, which is far over the kidney exclusion limit. Consequently, scFv:TRAIL should have a longer circulation half-life. Second, the antibody targeting domain will ensure enhanced tumor-accretion and retention [92-96]. Third, target-selective binding will convert the sTRAIL domain into a membrane-like form of TRAIL that can trigger apoptotic TRAIL-R1 but also TRAIL-R2 apoptotic signaling [97, 98]. The feasibility of this approach has been shown in vitro and in vivo for both solid tumors and leukemia [92-96]. Of note, scFv:TRAIL binding triggers TRAIL-receptor apoptotic signaling in a monocellular, as well as bi- or multicellular manner. Consequently, neighboring tumor cells that lack the target antigen can also be efficiently eliminated by the socalled bystander effect [99].

Rational choice of tumor target antigen will help optimize the efficacy of scFv:TRAIL-based therapeutics, as evidenced by a study using an EGFR-blocking antibody fragment. Here, the treatment of EGFR-positive tumor cells with scFv:TRAIL inhibited EGFR-mitogenic signaling and simultaneously induced TRAIL-apoptotic signaling [94]. In an 


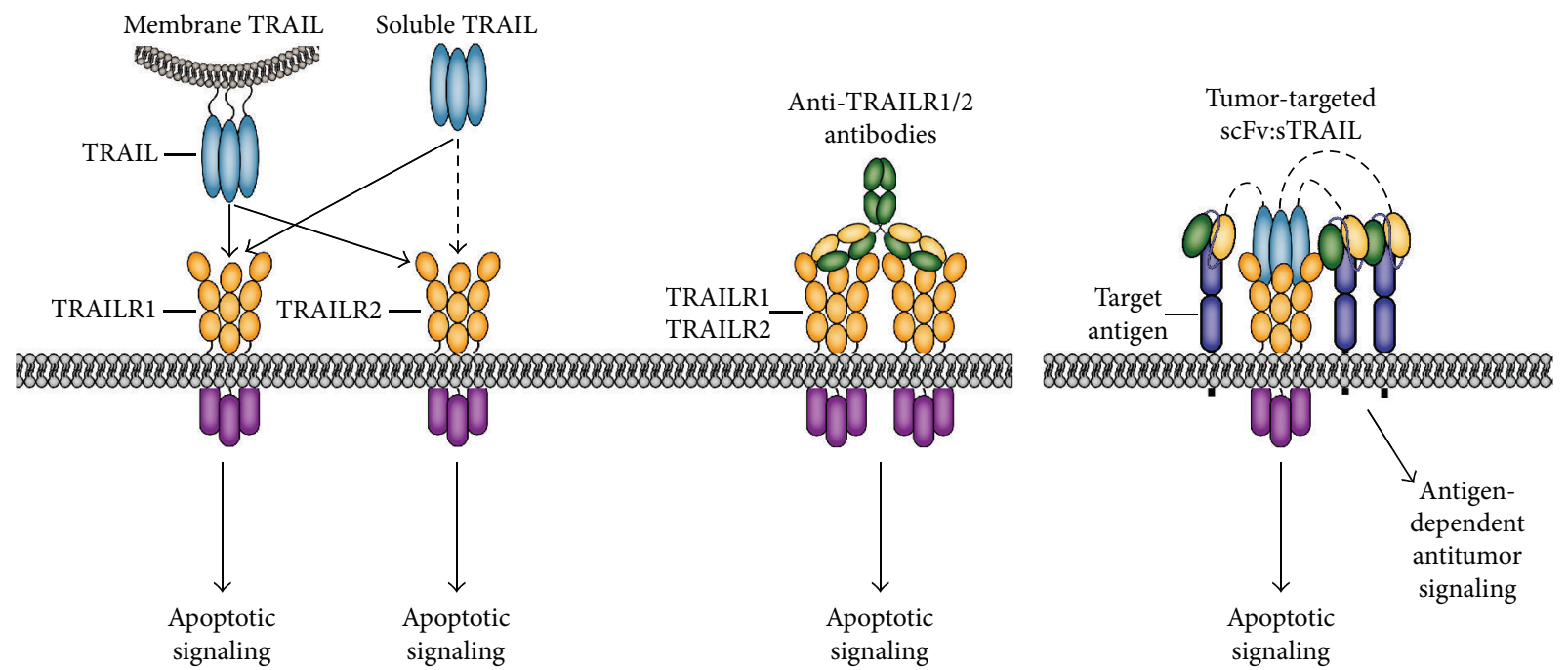

(a)

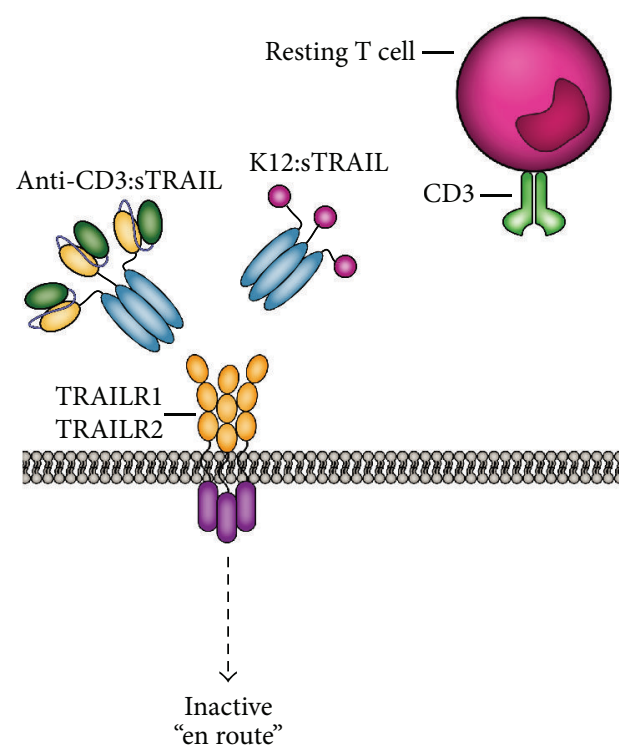

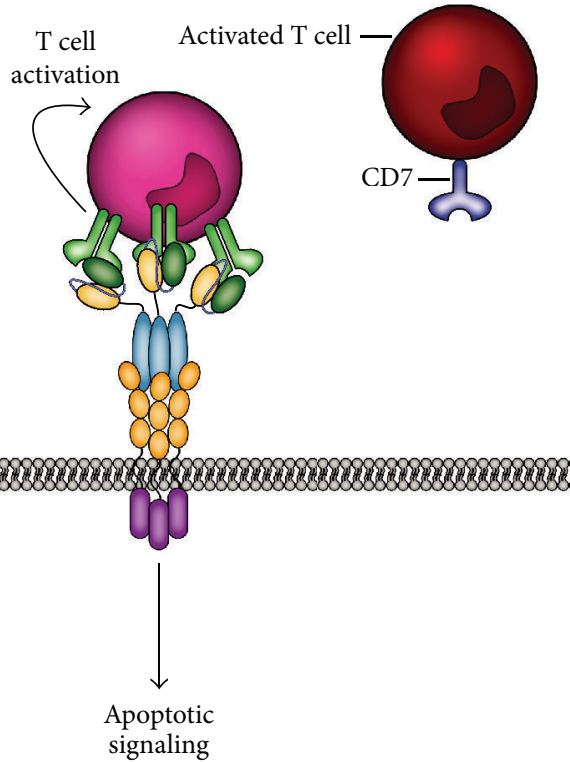

(c) (b)

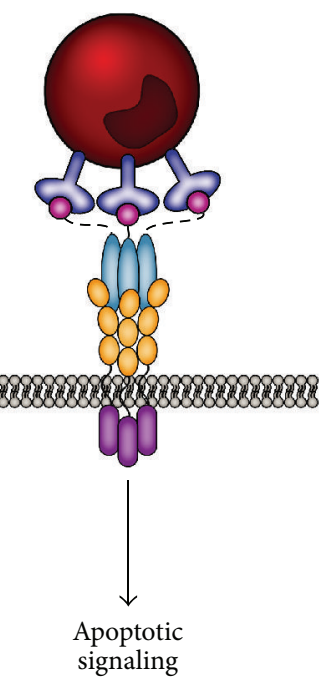

FIGURE 4: TRAIL/TRAIL-receptor signaling and design of TRAILR agonists. (a) Membrane expressed TRAIL triggers apoptotic signaling via TRAIL-R1 and TRAIL-R2, whereas soluble TRAIL only efficiently activates TRAIL-R1. Recombinant nontargeted sTRAIL thus predominantly triggers TRAIL-R1 apoptotic signaling. Recombinant TRAIL-R1 or TRAIL-R2 agonistic antibodies can selectively activate TRAIL-R1 or TRAIL-R2, respectively. (b) Tumor-targeted delivery of sTRAIL, using scFv:sTRAIL, results in conversion of sTRAIL to membrane-like TRAIL that can induce apoptosis via TRAIL-R1 and TRAIL-R2. The antibody fragment may inhibit or activate target antigen signaling and thereby contribute to the antitumor activity of scFv:sTRAIL. (c) Targeting of T-cell markers CD7 or CD3 with K12:TRAIL and antiCD3:TRAIL, respectively, equips T-cells with membrane-like proapoptotic TRAIL that enhances antitumor T-cell activity. The antiCD3 $\mathrm{scFv}$ can also trigger stimulatory signaling in resting T-cells and trigger granzyme/perforin-mediated cytotoxicity.

analogous fashion, targeting of the melanoma antigen MCSP (Melanoma-Associated Chondroitin Proteoglycan Sulphate) with an scFv:TRAIL fusion protein triggered dual MCSPinhibitory signaling and TRAIL apoptotic signaling [100]. MCSP is implicated in metastatic behavior of melanoma cells $[101,102]$. Interestingly, this fusion protein was $>100-$ fold more effective in colony formation assays that assess metastatic potential than in direct apoptotic assays. Furthermore, TRAIL inhibition only partly blocked the tumoricidal effect in colony formation assays, pointing to MCSP-related therapeutic effects. Thus, scFv-mediated tumoricidal activity can markedly contribute to the therapeutic activity of scFv:TRAIL fusion proteins.

In addition to direct tumor-targeting, the $\mathrm{scFv}$ targeting domain can also be used to selectively deliver TRAIL to the cell surface of immune effector cells, whereby these cells are equipped with an additional tumoricidal effector molecule (Figure 4(c)). In a proof of concept study, such 
T-cell targeted delivery of TRAIL, to the T-cell surface antigen $\mathrm{CD} 3$ or $\mathrm{CD} 7$, potentiated in vitro antitumor T-cell activity 500-fold and triggered potent tumoricidal activity in an in vivo engraftment model [103]. Of note, targeted delivery to $\mathrm{CD} 3$ on T-cells also triggered T-cell activation and potentiated intrinsic cytolytic granzyme/perforin pathway signaling. From this study it is apparent that rational choice of T-cell target antigen may be used to generate dual function scFv:TRAIL fusion proteins that on the one hand costimulate T-cells and on the other hand provide the TRAIL-apoptotic signal for tumor cell killing.

\subsection{Perspectives for Use of TRAIL in Cancer Immunotherapy.} From the above it is clear that nontargeted homotrimeric sTRAIL is safe, but also has sub-optimal apoptotic activity. Indeed, it is clear that design of combinatorial strategies of TRAIL with chemotherapy or other targeted drugs is warranted to achieve clinical efficacy. In preclinical studies, TRAIL activity is synergized by a plethora of different established and experimental anticancer drugs. A guideline for such clinical combinatorial TRAIL-based therapy may be the choice for a therapeutic that will block potential TRAILmediated prometastatic signaling via $\mathrm{NF} \kappa \mathrm{B}$ activation, as reported in preclinical studies for TRAIL-resistant pancreatic cancer cells [80]. NF $\kappa \mathrm{B}$ activation can be effectively blocked by clinically available proteasome inhibitors such as bortezomib [104]. For such combinatorial strategies, a lack of hepatocyte toxicity is particularly important, as aggregated forms of sTRAIL strongly reduce hepatocyte viability in vitro [105] and proteasome inhibition was shown to sensitize hepatocytes to sTRAIL [106]. Nevertheless, in this latter study hepatoma cells were significantly more sensitive and were eliminated at $>40$-fold lower bortezomib concentrations than normal hepatocytes, clearly highlighting a therapeutic window for this combination.

Inclusion of sTRAIL into an scFv:TRAIL fusion protein can be used to optimize both tumor-selective accretion and apoptotic activity, which may further be enhanced by rational incorporation of a tumoricidal $\mathrm{scFv}$. As for non-targeted TRAIL, combinatorial strategies may help to optimize activity. In this respect, a recent report identified promising synergy between bortezomib and an EGFRtargeted scFv:scTRAIL fusion protein towards hepatoma cells in the absence of toxic hepatocyte activity [107]. Further, depending on the relative contribution of the agonistic TRAIL receptors within a type of tumor, engineered sTRAIL variants that selectively trigger TRAIL-R1 or TRAIL-R2 may be used to enhance tumoricidal activity. For instance, the use of a designed TRAIL mutant with enhanced selectivity for TRAIL-R1 proved significantly more potent in $50 \%$ of EGFR-positive carcinoma cell lines analyzed [92]. Thus, contributory target antigen signaling as well as the tumor type intrinsic characteristics of TRAIL-R1/TRAIL-R2 signaling should be taken into account to identify the optimal scFv:TRAIL protein for respective tumor types.

Additional approaches to optimize TRAIL-based therapy include the engineering of a single chain TRAIL (scTRAIL) protein, in which three TRAIL monomers have been genetically linked [108]. This scTRAIL is a stable homotrimer and has been incorporated into an scFv:scTRAIL format that targets Her-2, with prominent Her-2 restricted in vitro and in vivo activity [108]. Of note, further genetic engineering of an EGFR-targeted scFv:scTRAIL yielded a dimerized EGFRtargeted scFv:scTRAIL (Db-scTRAIL) that proved to have 510 fold higher EGFR-restricted activity than the corresponding trimer form [109].

\section{Costimulatory TNF Ligands as Inducers of Effective Antitumor Immunity}

Development of the adaptive T-cell immune response is highly regulated and depends on an elaborate interplay between T-cell mediated recognition of antigens in the context of major histocompatibility complexes and the prevailing balance of co-stimulatory and immune-inhibitory signals. Unfortunately, this intricate multistep system of Tcell activation provides tumor cells with ample opportunity to interrupt this process. Indeed, tumor cells have been shown to hijack components of the T-cell co-stimulatory system and turn it against the infiltrating T-cell by downregulation of co-stimulatory and up-regulation of immune inhibitory signals [110]. In this situation, T-cell receptor interaction with peptide-loaded major histocompatibility complexes results in T-cell apoptosis or anergy and a halted tumor immune response. Further, many tumors have an altered T-cell balance, with, for example, an increased number of regulatory T-cells that serve to limit effector T-cell responses [111]. Overcoming these tumor-imposed brakes on immunity can help to reestablish antitumor immune responses. This is perhaps best evidenced by the strong clinical benefit of therapeutic antibodies against immune inhibitory signals, with the recent FDA approval of the antiCTLA4 antibody ipilimumab as well as the prominent clinical responses with antiPD-1 and PD-L1 antibodies reported in clinical trials with advanced stage cancer patients [112-114].

In addition, insufficient immune co-stimulatory signaling by tumor necrosis factor (TNF) and TNF-receptor (TNFR) superfamily members further limits the induction of effective antitumor T-cell immunity. Indeed, co-stimulatory TNFR signaling is pivotal for effective T-cell immunity and is also pursued as a therapeutic strategy to induce or restore effective antitumor immunity $[7,88]$. Proof of principle for the validity of this approach was first obtained over 2 decades ago using the TNF ligand Lymphotoxin- (LT) alpha. LT-alpha is a soluble ligand that binds to TNFR1 and TNFR2, but like sTNF only effectively stimulates TNFR1 $[115,116]$. Targeted delivery of LT-alpha induced de novo formation of lymphoidlike tissue in the tumor microenvironment, leading to T-cell mediated antitumor rejection. Unfortunately, LT-alpha also signals via TNFR1, with the potential for systemic effects as found for sTNF, which precludes its systemic administration to humans.

In the past decades several co-stimulatory TNFL/TNFR pairs have gained prominence as possible therapeutic modulators of T-cell immunity, in particular CD40L/CD40, 


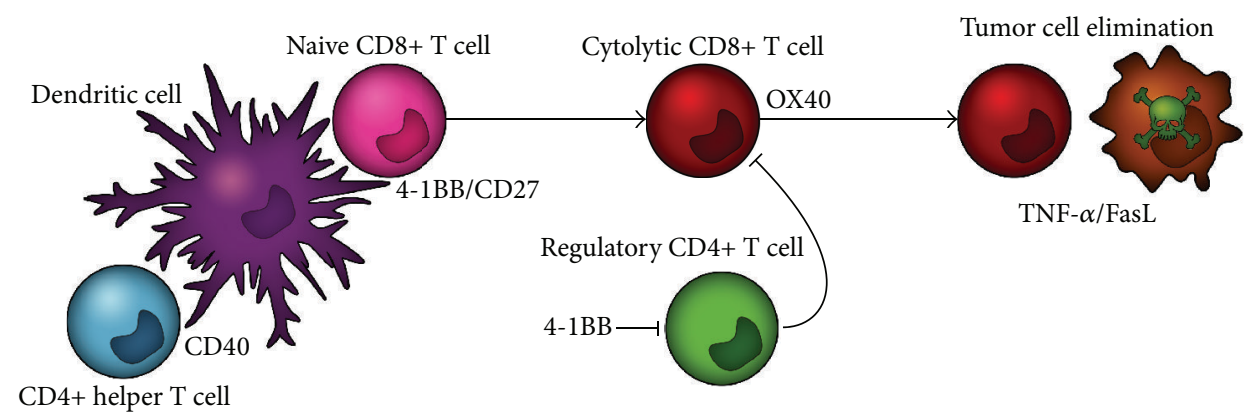

FIGURE 5: Co-stimulatory TNF ligands provide crucial signals for generation of antitumor T-cell responses. Within the antitumor T-cell immune response, CD40L-mediated CD40 costimulation of DCs by CD4+ T-helper cells is critical for the generation of CD8+ T-cell responses. 4-1BBL expressed on DCs stimulates the generation of T-cell response, while at the same time inhibiting the formation of inducible regulatory T-cells in the tumor micro-environment. CD70 serves to efficiently prime CD4+ and CD8+ T cell responses, to enhance T-cell survival, and to optimize effector function. OX40 is transiently upregulated upon T-cell activation and enhances clonal expansion, survival, proinflammatory cytokine production, and generation of memory CD4 T-cells and enhances CD8+ T-cell survival and expansion.

CD70/CD27, 4-1BBL/4-1BB, and OX40L/OX40 (Figure 5). These various TNF ligands provide a co-stimulatory signal at distinct stages of the immune response to ensure the ultimate generation of functional immunity [117]. A host of preclinical data indicated that reactivation of antitumor T-cell immune responses using agonistic antibodies that target respective costimulatory receptors triggers potent antitumor immunity in mouse studies.

However, an important concern with the use of agonistic antibodies that target the co-stimulatory TNFL/TNFR axis is the potential for deleterious side-effects due to ubiquitous TNFR signaling. Indeed, clinical trials with 4-1BB agonistic antibodies have been terminated after severe hepatic adverse events [118], while clinical trials with CD40 agonists were also associated with significant toxicity $[119,120]$. Thus, it is of great interest to design strategies that restrict co-stimulation and subsequent immune activation to the cancer lesion. In the section next I will discuss the biology of CD40L/CD40, CD70/CD27, 4-1BBL/4-1BB and OX40L/OX40 and highlight their current status for cancer immunotherapy. Further, I will discuss the rationale for incorporating these ligands into antibody-fragment targeted delivery of soluble TNFLs to the tumor.

\section{CD40L Biology}

$\mathrm{CD} 40 \mathrm{~L}$ is a type II transmembrane protein transiently expressed on activated CD4+, CD8+, and $\gamma \delta$ T-cells [121]. Further, CD40L expression has been identified on monocytes, activated B-cells, epithelial cells, endothelial cells, platelets, smooth muscle cells, and DCs. Expression of its cognate receptor CD40 is found on B-cells, monocytes, macrophages, platelets, DCs, eosinophils, and activated CD8+ T-cells [122-124].

One of the main functions of the CD40L/CD40 system is to activate and "license" DCs to prime effective cytotoxic CD8+ T-cell responses $[125,126]$. In brief, costimulatory CD40L on antigen-specific CD4+ T helper cells interacts with CD40 on DCs, which triggers a multipronged response with upregulation of CD40, increased DC survival, upregulation of T-cell co-stimulatory molecules CD80 and CD86, an increase in the expression and stability of MHC class II-peptide complexes, and induction of inflammatory cytokines, such as immunostimulatory cytokine IL-12 [127, 128]. Together, these effects serve to "license" DCs and to stimulate the generation of effective CD8+ T-cell response.

In the absence of CD40 signaling, activation of CTLs by so-called "unlicensed" DCs induces T-cell anergy or T-cell deletion and generates regulatory T cells [129]. Importantly, induction of CD40 signaling on DCs using, for example, agonistic antibodies can substitute for CD4+ T-cell help and directly stimulate a specific CD8+ CTL response [125, 130], highlighting a clear rationale for CD40-based cancer immunotherapy.

6.1. Triggering CD40L/CD40 Signaling for Cancer Therapy. The major aim of therapeutic targeting of CD40 is the induction of efficient DC-mediated priming of T-cell immunity and ensuing induction of effective antitumor T-cell immune responses. This aim has been pursued using various approaches, first and foremost with agonistic antibodies and recombinant forms of soluble CD40L (Figure 6). A human CD40L variant fused to an isoleucine zipper trimerization domain yielded prominent induction of T-cell immunity and tumoricidal activity in preclinical models (Figure 6) [131]. Similarly, agonistic CD40 antibodies yielded potent antitumor T-cell immunity in mice [132]. Both recombinant CD40L and an agonistic antiCD40 antibody (CP-870.893) advanced into early stage clinical trials in cancer patients [119, 120]. In these clinical trials, systemic treatment was associated with significant and dose-limiting toxicity, with the MTD of sCD40L already reached at the low dose of $0.1 \mathrm{mg} / \mathrm{kg}$. Nevertheless, CP-870.893 induced partial responses in 15\%$20 \%$ of advanced stage melanoma and pancreatic adenocarcinoma patients [133-135], highlighting the promise of CD40 targeting.

Of note, CD40 is also expressed on various malignancies [136]. On many of these malignant cells, the cross-linking of CD40 triggers apoptotic cell death or inhibits proliferation, as for instance, seen upon CD40L treatment of primary 


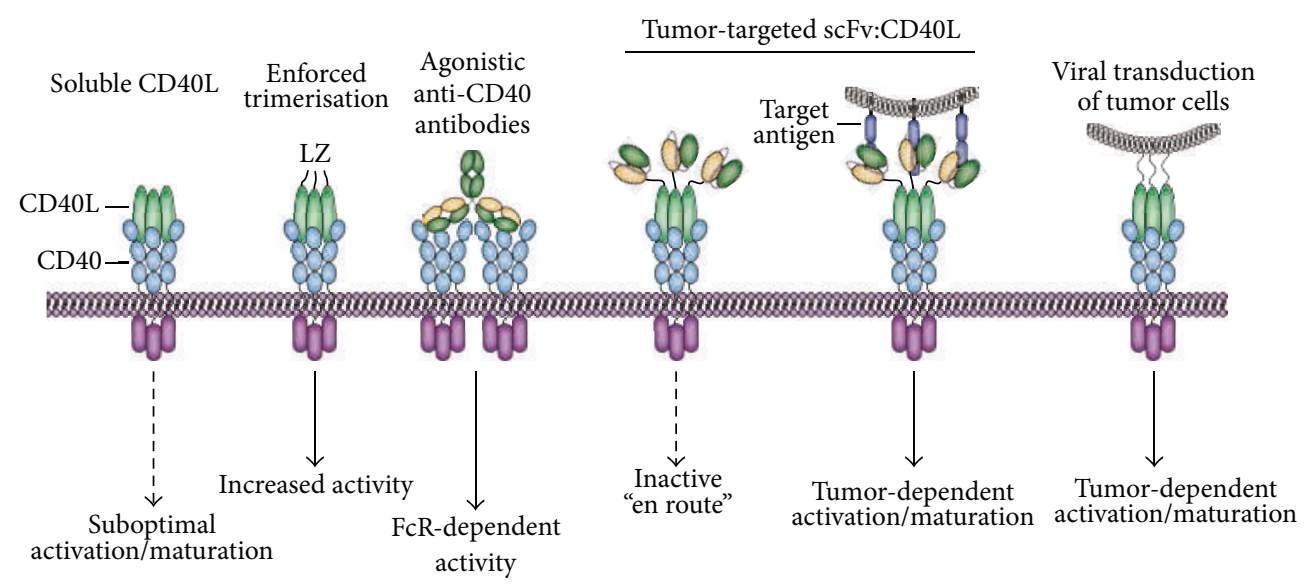

Figure 6: CD40L/CD40-based agonists for cancer therapy. Soluble CD40L is only capable of sub-optimal CD40 signaling. However, enforced trimerization of CD40L or agonistic antiCD40 antibodies can trigger effective CD40-signaling, but with severe side-effects due to ubiquitous CD40-activation. Of note, CD40 agonist antibodies require FcR-mediated cross-linking for effective CD40-signaling. In an antibody fragment-targeted scFv:CD40L fusion protein, the CD40L domain is relatively inactive en route, but gains membrane-like activity upon target antigen-mediated binding. Further, CD40L can be virally transduced into tumor cells, using AdCD40L, to optimize CD40mediated co-stimulation.

ascites-derived ovarian carcinoma cells [137]. This contrasts with the typical CD40-mediated prosurvival and proliferative signaling on normal human cells. CD40-mediated inhibition of proliferation has also been observed in high grade B-cell lymphoma derived cell lines in vitro as well as in vivo, suggesting that cytotoxic antiCD40 therapy is a potential strategy for B-cell lymphoma. In line with this, the antiCD40 antibodies dacetuzumab (SGN-40) and lucatumumab (HCD122) are being evaluated in various phase I/II trials [88]. Thus CD40 targeted therapy may have a dual beneficial effect comprising direct tumor cell signaling, leading to growth arrest or even apoptosis, and DC-dependent stimulatory activity on antitumor T-cell immunity.

\subsection{Targeted CD40L/CD40-Based Cancer Immunotherapy.} Despite the obvious promise of CD40-targeted immunotherapeutics, the applicability is hampered by systemic and doselimiting toxicity towards normal cells in patients. Indeed, agonist antiCD40 treatment of mice was already associated with considerable inflammatory side effects. Thus, to further advance $\mathrm{CD} 40$ as a therapeutic target it is imperative to enhance the selectivity of CD40 stimulation. Accumulating evidence indicates that CD40 signaling is only initiated when CD40 is clustered within the membrane of target cells. In fact, CD40 signaling induced by antiCD40 antibodies critically depends on $\mathrm{Fc}$-receptor positive cells that provide requisite Fc-mediated clustering of CD40 [138]. Thus, in the absence of sufficient cross-linking the antiCD40 signal is ineffective in generating immunostimulatory signals (Figure 6). For soluble CD40L (sCD40L), evaluation of cross-linking requirements revealed that a trimeric Flag-tagged form of sCD40L could already trigger CD40-signaling [139]. Nevertheless, the efficacy of signaling was increased $\sim 10$-fold upon antiFlag antibody-mediated cross-linking. In line with this finding, a hexameric form of sCD40L proved fully capable of activating
DCs and inducing T-cell responses [139, 140]. Analogously, an oligomeric surfactant protein D (SP-D) CD40L fusion protein efficiently triggered $\mathrm{CD} 40$-dependent $\mathrm{B}$-cell proliferative effects, whereas trimeric sCD40L proved minimally active [141]. This oligomeric form of CD40L was recently found to also effectively stimulate antiHIV immune responses in combination with an HIV-1 Gag vaccine [142].

Based on these cross-linking requirements for CD40/ C40L signaling, CD40L has also been included in a FAPtargeted scFv:CD40L antibody fragment-based fusion protein (Figure 6) [139]. In brief, antibody fragment-specific delivery will ensure FAP-specific accretion and the subsequent display of multimeric/oligomerized CD40L for effective induction of CD40 signaling on DCs. Indeed, FAP-specific binding of scFv:CD40L triggered an $~ 25$-fold decrease in ED50 for IL-8 production in target cells.

In addition to systemic treatment with CD40 agonists various alternate $\mathrm{CD} 40$-based strategies have been investigated in order to optimize DC activity. Of those, adenoviralbased immunostimulatory gene therapy using AdCD40L is of particular interest (Figure 6) [143]. In brief, adenoviral infection will trigger Toll-like receptor (TLR) signaling, while the transgene CD40L potentiates DC activity. AdCD40L can be used for ex vivo gene modification of tumor cell vaccines or for direct intratumoral injection and has proven efficacious in murine models. Further, AdCD40L proved safe in humans and induced clinical responses in early clinical trials [144146].

In an alternative approach to optimize DC vaccination a bi-specific co-stimulatory diabody comprising antiCD40 and antiCD28 was constructed [147]. This diabody was designed to simultaneously target and activate stimulatory CD40signaling on DCs and CD28-signaling on naïve T cells. Using this diabody, the strength and duration of T cell/AML$\mathrm{DC}$ interactions and the responsiveness of T-cells to AML 
antigens was increased. In addition, CD40L can be genetically fused to a vaccine antigen in order to enhance the immunogenicity of the vaccine. For instance, transfection of DCs with a plasmid containing a genetic fusion between the Hepatitis B virus (HBV) S gene and CD40L upregulated DC maturation markers, triggered IL-12 secretion, and stimulated allogeneic T-cell proliferation [148]. Finally, the previously described multimeric SP-D-CD40L fusion protein was recently using in an adoptive T-cell expansion protocol, in which it efficiently expanded and generated APC-like B-cells ex vivo that could trigger CD8+ T-cell expansion $[149,150]$.

\subsection{Perspectives for sCD40L/CD40 in Cancer Immunotherapy.} Agonistic triggering of CD40 holds considerable promise as an anticancer therapeutic strategy and likely will trigger both direct antiproliferative and/or proapoptotic signaling in CD40-positive tumor cells as well as induction of antitumor T-cell immune responses. A main current focus of CD40 agonist research is on the design and evaluation of combined therapy of CD40 agonists with, for example, chemotherapy or other immunomodulators such as antiCTLA-4 antibody.

For the clinical use of agonistic CD40 therapeutics it is imperative to achieve higher tumor selectivity to ensure an acceptable toxicity profile. Of interest in this respect is a recent report in which antiCD40 antibody was given at low-dose intra or peritumorally in a slow-release formulation [151]. This strategy resulted in local activation of tumorspecific CD8+ T cells without causing systemic toxicity by nonspecific and ubiquitous CTL activation. Enhanced tumor selectively can also be achieved by antibody-targeting strategies such as the scFv:CD40L fusion protein referred to earlier [139]. Further, the requirement of CD40 agonistic antibodies for FcR-mediated cellular cross-linking opens the possibility of generating bi-specific antibodies that on the one hand target a tumor associated antigen and on the other hand comprise an antiCD40 antibody fragment. In principal, CD40 signaling will only be initiated upon tumor specific binding of the bi-specific antibody fragment thus ensuring a restricted CD40 co-stimulatory signaling.

Potential advances on DC-targeted vaccination strategies include CD40L delivery to tumor cells using an oncolytic adenoviral vector $[152,153]$. Infection of tumor cells with oncolytic vectors will trigger tumor cell death, thereby boosting tumor antigen release in the tumor micromilieu, while the CD40L transgene is designed to ensure optimal DC/Tcell interaction $[152,153]$.

Of note, although it is clear that CD40/CD40L signaling can potently augment antitumor immune responses, recent studies also highlight a potential immunosuppressive effect of soluble trimeric CD40L [154]. The serum of cancer patients contains significantly elevated levels of sCD40L compared with healthy donors [155]. Further, recombinant trimeric sCD40L triggered enrichment of myeloid-derived suppressor cells (MDSCs), expansion of $\mathrm{T}_{\text {reg }}$, and inhibited effector T-cell proliferation [155]. These findings highlight the importance of evaluating possible unanticipated immune inhibitory effects of sub-optimal CD40 activation by CD40L-based agonists and of the influence of serum sCD40L on therapy outcome.
This may ultimately lead to inclusion of serum CD40L as a patient stratification marker.

\section{CD70/CD27 Biology}

The ligand CD70 (also known as CD27L) is a predicted type II homotrimeric transmembrane family member of the TNF family $[156,157]$. Unlike most other TNF ligands, CD70 has not been found to contain putative cleavage motifs in the extracellular domain and is thus expected to exist only as a transmembrane protein. The expression of CD70 on normal cells is restricted to activated $\mathrm{T}$ - and B-lymphocytes and mature DCs [158].

The cognate receptor for CD70 is CD27, a type I transmembrane receptor expressed on naive $\mathrm{T}$ cells, mature $\mathrm{T}$ cells, memory B-cells, and NK-cells [158]. Cross-linking of CD27 triggers recruitment of the adaptor proteins TRAF2 and TRAF5 to its cytoplasmic domain, leading to activation of canonical and noncanonical $\mathrm{NF} \kappa \mathrm{B}$ signaling and c-Jun kinase signaling. Of note, CD27 is expressed as a homodimer on the cell surface [159], suggesting that functional CD70/CD27 interaction occurs at least in a hexameric form. In contrast to CD70, CD27 can be proteolytically processed into a soluble form that may serve as a competitive inhibitor [160].

The key biological function of CD70 is to efficiently prime CD4+ and CD8+ T cell responses, to enhance T-cell survival, and to optimize effector function [158, 161-163]. As such, CD70 appears to be a crucial co-stimulatory molecule that is required for the induction of $\mathrm{T}$ cell immune responses [158]. In particular, CD27 is present on resting T-cells and is further upregulated upon T-cell activation $[156,164,165]$. This upregulation of CD27 on effector T-cells is transient and strongly correlates with effector function [166]. In line with a critical role for CD27 in T-cell activation, both primary and secondary $\mathrm{T}$ cell responses are impaired in $\mathrm{CD} 27^{-/-}$ mice [167]. CD70/CD27 signaling promotes the development of CD4+ T-cells producing either $\mathrm{T}_{\mathrm{H}} 1$ or $\mathrm{T}_{\mathrm{H}} 2$ type effector cytokines [168], suggesting that CD70/CD27 signaling can trigger a broad spectrum of immune responses.

7.1. CD70/CD27 as Targets for Cancer Immunotherapy. Many types of hematological and solid tumors have been documented to express CD70 on the cell surface [169], whereas CD70 is only transiently expressed on antigen-activated lymphocytes on normal cells. This expression pattern establishes CD70 as a potential target for antibody-based cancer therapy (Figure 7). Indeed, antiCD70 antibodies have shown considerable preclinical efficacy towards hematological malignancies. For instance, the humanized IgG1 antibody SGN70 eliminated CD70-positive tumor cells leading to tumor regression in disseminated lymphoma and multiple myeloma xenograft models [170], in this case via typical antibody effector functions, such as ADCC and CDC.

In addition to its tumor-restricted expression pattern research has focused on the potential reactivation of antitumor T-cell immunity by agonistic CD27-targeted therapy (Figure 7). The rationale for this approach is emphasized by the more efficient $\mathrm{T}$-cell response in human CD70 transgenic 


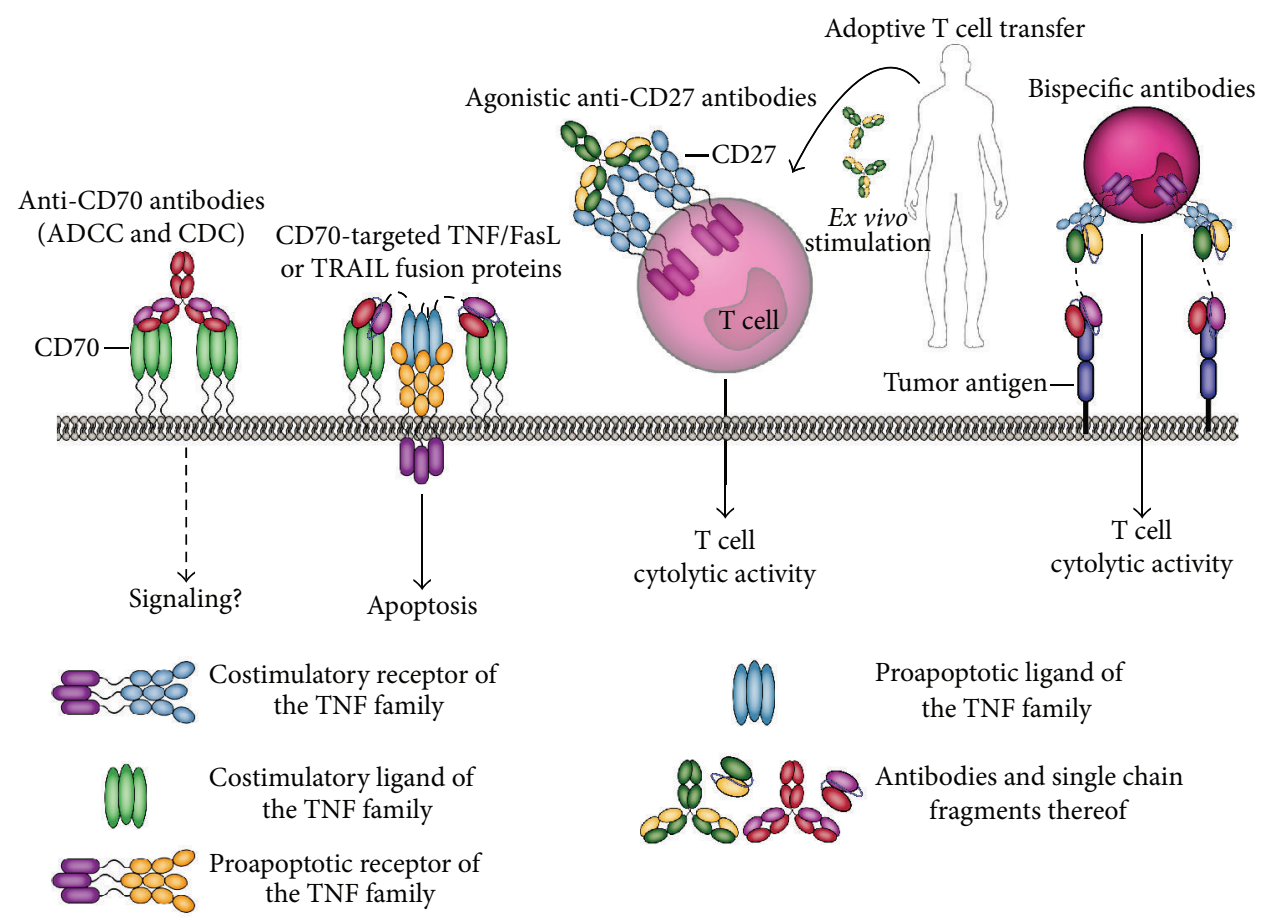

FIGURE 7: CD70/CD27-based agonists for cancer therapy. CD70 is highly expressed on malignant cells and thus a bona-fide target for antiCD70 antibody based therapy. Similarly, scFv-targeted TRAIL/FasL-based fusion proteins could be used to selectively deliver and locally activate proapoptotic signaling. Triggering CD27 T-cell co-stimulatory signaling may be particularly applicable in, for example, ex vivo expansion of adoptive T-cells. Incorporation of an antiCD27 scFv in a bispecific antibody format with a tumor-specific targeting antibody fragment may open up ways to ensure selective modulation and/or inhibition of CD27 signaling in the tumor micro-environment.

mice upon tumor challenge [161]. Correspondingly, agonistic triggering of CD27-signaling ensured generation of a tumorspecific T-cell response and protected against lymphoma, melanoma, and fibrosarcoma tumor growth upon i.v. or s.c. tumor challenge $[161,171-173]$.

However, a recent study identified that in established tumor models, CD27 signaling actually promoted tumor growth, with a reduction in $\mathrm{T}_{\text {reg }}$ apoptosis and production of the $\mathrm{T}_{\text {reg }}$ survival cytokine IL- 2 by CD4+ effector $\mathrm{T}$ cells $\left(\mathrm{T}_{\mathrm{Eff}}\right)$ [173]. In line with this, the frequency of $\mathrm{T}_{\text {regs }}$ and the growth of solid tumors was reduced in CD27-deficient mice or in wild-type mice treated with an antagonistic CD27 monoclonal antibody. Indeed, such a CD70-mediated expansion of $\mathrm{T}_{\text {regs }}$ corroborates with the proposed role of CD70 in tumor immune escape in renal cell carcinoma [174]. Thus, in the tumor micro-environment CD70 may promote tumor growth and immune evasion.

7.2. Perspectives for CD70/CD27 in Cancer Immunotherapy. CD70 is highly expressed on various types of cancers and as such is a bona fide target for antiCD70 antibody mediated therapy. Thus, antiCD70 antibodies are well-positioned for, for example, B-cell lymphoma, where preclinical data revealed potent tumoricidal activity [170]. Due to its selective expression profile CD70 may also be a target for design of TRAIL, FasL, or TNF- (prodrug-) based antibody fragmenttargeted fusion proteins as well as antibody-drug conjugates/immunotoxins (Figure 7). Further advances in CD70 cytotoxic therapy can be anticipated for combination with, for example, cytotoxic debulking therapy.

However, caution is required in terms of exploiting the immunoregulatory role of CD70/CD27 for cancer immunotherapy. Although the CD70/CD27 axis has prominent immunostimulatory activity in de novo induced immune responses, its role in the established tumor microenvironment appears paradoxically opposite, with the expansion and prolonged survival of $\mathrm{T}_{\text {regs }}$ [173]. Thus, it is imperative to consider the aim of CD70/CD27-based immunotherapy and adapt the strategy accordingly. For instance, upon inclusion in, for example, tumor vaccination strategies, where a de novo antitumor T-cell response is induced, adjuvant use of a CD27 agonist may help optimize T-cell responses. Similarly, ex vivo expansion of T-cells for subsequent adoptive T-cell transfer experiments may benefit from CD27 agonists (Figure 7). In contrast, in a combination approach of CD70/CD27 targeting with conventional cytotoxic therapy, it may be more appropriate to incorporate an antagonistic CD27 antibody. Hereby, the $\mathrm{T}_{\text {reg }}$-induced brake on existing $\mathrm{T}$ cell immunity is released. Of note, incorporation of CD27 in a bispecific antibody format with a tumor-specific targeting antibody fragment may open up ways to ensure selective modulation and/or inhibition of CD27 signaling in the tumor micro-environment (Figure 7). Further preclinical studies are needed to evaluate whether this dualistic and contextdependent use of CD70/CD27 for cancer therapy is feasible. 


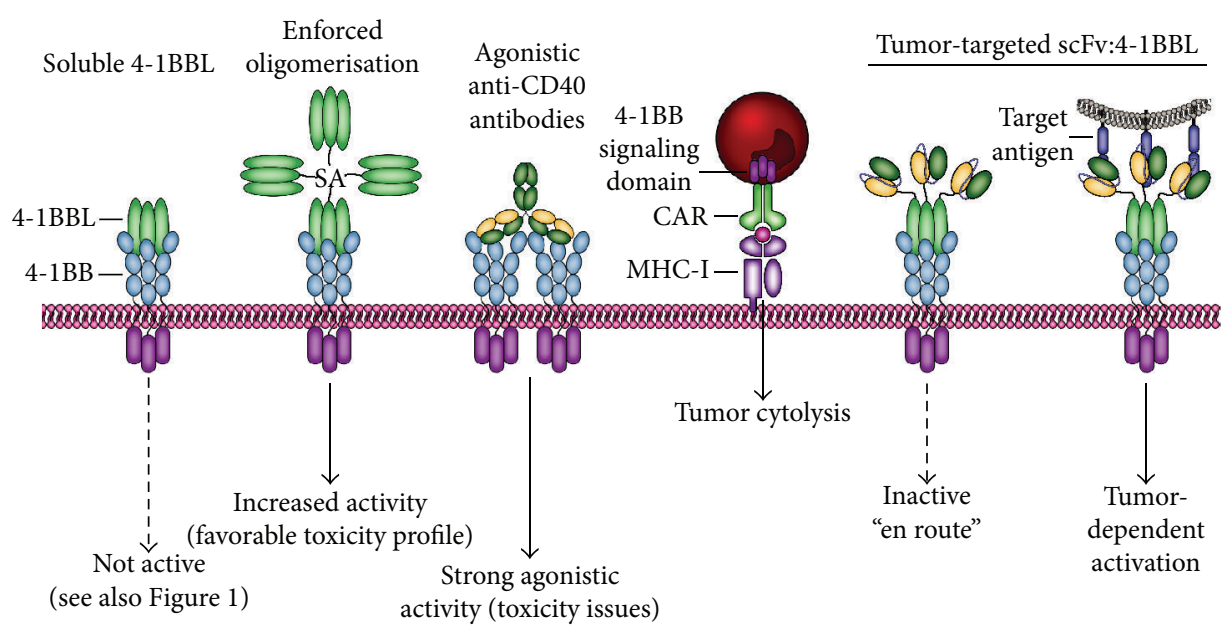

FIGURE 8: 4-1BBL/4-1BB. Soluble 4-1BBL or hexameric 4-1BBL is essentially inactive. However, enforced oligomerization using SA-4-1BBL enables $4-1 \mathrm{BB}$ activation with a favorable toxicity profile. In contrast, agonistic 4-1BB antibodies potently activate 4-1BB signaling but with dose-limiting toxicity. The selective use of 4-1BB co-stimulatory signaling can potentiate CAR T-cell activity and trigger effective lysis. Further, selective delivery of 4-1BBL using scFv:4-1BBL ensures target antigen-restricted conversion of inactive s4-1BBL into membrane-like and signaling competent $4-1 \mathrm{BBL}$.

\section{4-1BBL/4-1BB Biology}

4-1BB (also known as CD137) is an inducible co-stimulatory receptor expressed on activated T-cells as well as activated NK-cells but is constitutively expressed on regulatory $\mathrm{T}$ cells [175]. In fact, 4-1BB expression has been used in a recent study as a marker to identify and isolate natural $\mathrm{T}_{\text {reg }}$ from peripheral blood mononuclear cells [176]. The ligand for 4-1BB, 4-1BBL, is predominantly expressed on activated antigen presenting cells such as Dendritic cells, B-cells and macrophages [175]. Interestingly, DCs not only express 4$1 B B L$, but can also express $4-1 \mathrm{BB}$ upon activation although the consequence of this co-expression is unclear. Co-stimulatory signaling by $4-1 \mathrm{BBL} / 4-1 \mathrm{BB}$ proceeds via recruitment of TRAFs to the cytoplasmic domain of 4-1BB [177], which triggers downstream activation of $\mathrm{NF} \kappa \mathrm{B}, \mathrm{PKB}$, and $\mathrm{PI} 3 \mathrm{~K}$ pathways and upregulates antiapoptotic proteins such as Bcl$\mathrm{xL}[178,179]$.

The inducible expression of 4-1BBL on APCs and 4-1BB on T-cells implied an important role for this ligand/receptor pair in T-cell co-stimulation. Indeed, 4-1BB triggering on T-cells using either an agonistic anti4-1BB antibody or recombinant $4-1 \mathrm{BBL}$ enhanced the proliferation as well as the cytokine secretion in vitro in both CD4+ and CD8+ T-cells $[180,181]$. However, 4-1BB co-stimulatory activity appears to preferentially expand CD8+ T cells over CD4+ T cells [182], with enhanced CD8 $\mathrm{T}$ cell survival and inhibition of activation-induced cell death [179, 183-185]. In line with this, $4-1 \mathrm{BBL}^{-/-}$mice are characterized by a decreased CD8specific T-cell response [186-188].

\subsection{Triggering 4-1BB/4-1BBL Signaling for Cancer Therapy.}

The 4-1BBL/4-1BB co-stimulatory axis has a multifold effect on cancer immunology and has therefore been a prime target for therapeutic manipulation, also based on the finding that various tumor infiltrating T-cells express 4-1BB [189]. Agonistic 4-1BB antibodies trigger effective antitumor immune responses in a variety of mouse models (Figure 8) [190, 191]. However, ubiquitous activation of co-stimulatory 4$1 \mathrm{BB}$ signaling was associated with severe toxicity in murine models [192, 193]. Indeed, although in an initial phase I trial the anti4-1BB antibody (BMS-663513) had tolerable side effects, a follow-up Phase II trial revealed severe liver toxicity in $\sim 10 \%$ of the patients, with 2 fatalities at doses $>1 \mathrm{mg} / \mathrm{kg}$. As a consequence, trials with systemic agonistic anti4-1BB antibody were terminated, although a doseescalation study has resumed (NCT01471210). These data point to the fact that more tumor-selective 4-1BB activation is needed. In this respect, a recombinant fusion protein comprising streptavidin (SA) fused to murine soluble 4$1 B B L$, yielding oligomeric 4-1BBL proved safe and effective in murine models (Figure 8) [194]. SA-4-1BBL was also reported to inhibit the formation of induced $\mathrm{T}_{\text {reg }}\left(\mathrm{iT}_{\text {reg }}\right)$, that normally limit T-cell immune response in the tumor microenvironment, and to make CD4+ and CD8+ effector T-cells $\left(\mathrm{T}_{\mathrm{Eff}}\right)$ cells refractory to $\mathrm{T}_{\text {reg }}$ activity [195]. Consequently, the intratumoral $\mathrm{T}_{\mathrm{Eff}} / \mathrm{T}_{\text {reg }}$ cell ratio increased, which correlated with therapeutic efficacy in various preclinical tumor models. Such an elevated $\mathrm{T}_{\mathrm{Eff}} / \mathrm{T}_{\text {reg }}$ ratio is predictive of survival in various types of cancer, for example, in ovarian cancer patients [196].

Of note, SA-4-1BBL has also been positioned for vaccination strategies, in which biotinylated primary isolated tumor cells can be rapidly loaded with 4-1BBL [197]. Here, 4-1BBL provided co-stimulation and optimized vaccine-mediated $\mathrm{T}$ cell immune responses. The efficacy of DC-based vaccines can also be enhanced by gene-pulsing DCs ex vivo with 41BBL [198]. Such 4-1BBL expressing DCs trigger enhanced T-cell activation and increased IFN- $\gamma$ production, suggesting 
that $4-1 \mathrm{BBL}$ is a suitable adjuvant to optimize DC-based cancer immunotherapy.

4-1BB signaling has also been exploited to enhance the efficacy of so-called Chimeric Antigen Receptor (CAR) Tcells. In brief, a CAR is a T-cell transduced with a modified T-cell receptor that comprises the intracellular signaling domain of the $\mathrm{CD} 3$ zeta chain fused to an extracellular antitumor scFv antibody fragment [199]. This antitumor antibody fragment retargets the CAR to tumor cells, whereupon the CD3 zeta chain triggers T-cell activation. More recent CAR T-cells have been engineered to additionally contain the intracellular signaling domain of 4-1BB, which provides a second co-stimulatory signal (Figure 8). A recent clinical trial with a CD19 specific CAR yielded exciting effects, with the infusion of moderate dose autologous CAR T-cells triggering therapeutic activity in all three advanced CLL patients and a complete remission in 2 of the patients $[200,201]$. An important cautionary note for including costimulatory domains in CAR T-cells was learned when an Her2-specific CAR containing dual intracellular 4-1BB and CD28 co-stimulatory domains proved fatal upon infusion in the patient [202].

The 4-1BBL/4-1BB co-stimulatory axis has been mainly investigated in terms of T-cell immune responses. However, the antitumor efficacy of 4-1BB stimulation in mice appears to partly rely on NK-cell activity [203]. In line with this, ex vivo stimulation of PBMCs of healthy donors or patients with renal cell or ovarian carcinoma with a combination of soluble 4-1BBL and IL-12 induced a long-term proliferation of functional CD56 ${ }^{\text {bright }}$ NK cells [204]. These data further confirm the role of 4-1BBL/4-1BB in NK-cell biology and highlight that inclusion of s4-1BBL may optimize ex vivo expansion and activation of NK cells for cancer immunotherapy.

8.2. Targeted 4-1BBL-Based Cancer Immunotherapy. As with the other ligand/receptor pairs discussed in this review, both $4-1 \mathrm{BB}$ and $4-1 \mathrm{BBL}$ are naturally occurring homotrimers. However, activation of 4-1BB with 4-1BBL requires oligomerization, with trimeric soluble 4-1BBL being approximately 100 -fold less active than oligomerized 4-1BBL [139]. This differential activity profile positions $4-1 \mathrm{BBL}$ as a potential effector domain for antibody fragment-targeted immunotherapy. Indeed, proof of concept for restricted activation of 4-1BBmediated co-stimulation was obtained for targeted delivery of $4-1 \mathrm{BBL}$ to the tumor stroma marker FAP using an scFvFAP1BBL fusion protein (Figure 8) [205]. In cocultures of FAPexpressing HT1080 cells and T-cells, the fusion protein provided co-stimulatory signals. In contrast, in cocultures with parental FAP-negative HT1080 and T-cells, scFvFAP:4$1 \mathrm{BBL}$ was inactive. Together, these reports indicate that target cell-dependent co-stimulation with scFv:4-1BBL may enhance tumor-restricted T-cell activation and improve $\mathrm{T}$ cell-mediated antitumor immunity.

8.3. Perspectives for 4-1BBL/4-1BB in Cancer Immunotherapy. Although systemic 4-1BB treatment is associated with severe toxicity, the $4-1 \mathrm{BB} / 4-1 \mathrm{BBl}$ axis remains of great interest and various approaches may be used to increase tumor specificity. For instance, a recent report explored spatiotemporal infusion of adoptive T-cell transfer and 4-1BB. In brief, adoptively transferred T-cells were first infused and were found to upregulate 4-1BB expression only at the site of tumor, thus yielding a therapeutic window for 4-1BB agonist treatment 3 days after lymphocyte infusion [206]. In addition, combined use of 4-1BBL with T-cell retargeting strategies may yield an MHC-unrestricted potent antitumor immune response. The potential for such a strategy has been recently shown, with a combination of T-cell retargeting bispecific antibody and scFv:4-1BBL fusion protein, yielding a strongly enhanced cytotoxic T-cell response [207]. In brief, the bispecific antibody provided MHC-unrestricted tumor recognition and the primary CD3-mediated activation signal, whereas endoglintargeted 4-1BBL provided the crucial second T-cell activation signal. Further, combination of a 4-1BBL-expressing tumor cell vaccine with antibody-mediated blockade of CTLA-4 proved superior to tumor cell vaccine alone [208]. Here, the combination triggered regression of established tumors and yielded a significant increase in survival in mice. Similarly, tumor targeted delivery using scFv:4-1BBL may be used to maximize CAR T-cell activity. Here, sequential dosing may help to optimize tumor-restricted CAR activation and improve on the safety profile of the CAR technology.

\section{OX40L/OX40 Biology}

Another prominent candidate for the (re)activation of active T-cell immunity is the ligand/receptor pair OX40L/OX40. OX40 (CD134) was named after the antibody clone OX40 that was originally used to identify this receptor on activated CD4+ T-cell blasts [209]. OX40 was later also identified on CD8+ T-cells, NK cells, NKT cells, and neutrophils [210]. OX40L is primarily expressed on antigen presenting cells, such as DCs, B-cells, and macrophages, but is also expressed on freshly isolated NK-cells where it is further upregulated upon activation [211]. In addition, OX40L is expressed on the basal side of endothelial cells at sites of inflammation, where it may provide a crucial co-stimulatory signal to extravasated T-cells.

OX40 intracellular signaling proceeds in particular via TRAF2 and TRAF5 and activates downstream canonical and noncanonical NF $\kappa$ B signaling, PI $3 \mathrm{~K}$ and PKB pathways. OX40 signaling upregulates the antiapoptotic proteins $\mathrm{Bcl} 2$, Bcl-xL, and survivin 4-6 days following TCR-ligation and thereby provides a crucial survival signal to $\mathrm{CD} 4+$ and $\mathrm{CD} 8+$ $\mathrm{T}$-cells [212-214]. Indeed, in OX40 ${ }^{-1-} \mathrm{T}$-cells the expression of these antiapoptotic proteins is downregulated [212]. OX40 provides a co-stimulatory signal to sub-optimally and lowdose TCR-stimulated T-cells and enhances clonal expansion, survival, proinflammatory cytokine production, and generation of memory CD4 T-cells [215-218]. Further, OX40 also directly enhances CD8+ T-cell survival and expansion as well as indirectly stimulates CD8+ T-cell expansion via induction of CD4+ T-cell helper responses [219, 220].

Importantly, expression of OX40 on T-cells is transient and first becomes detectable $\sim 12-24 \mathrm{~h}$ after T-cell receptor 


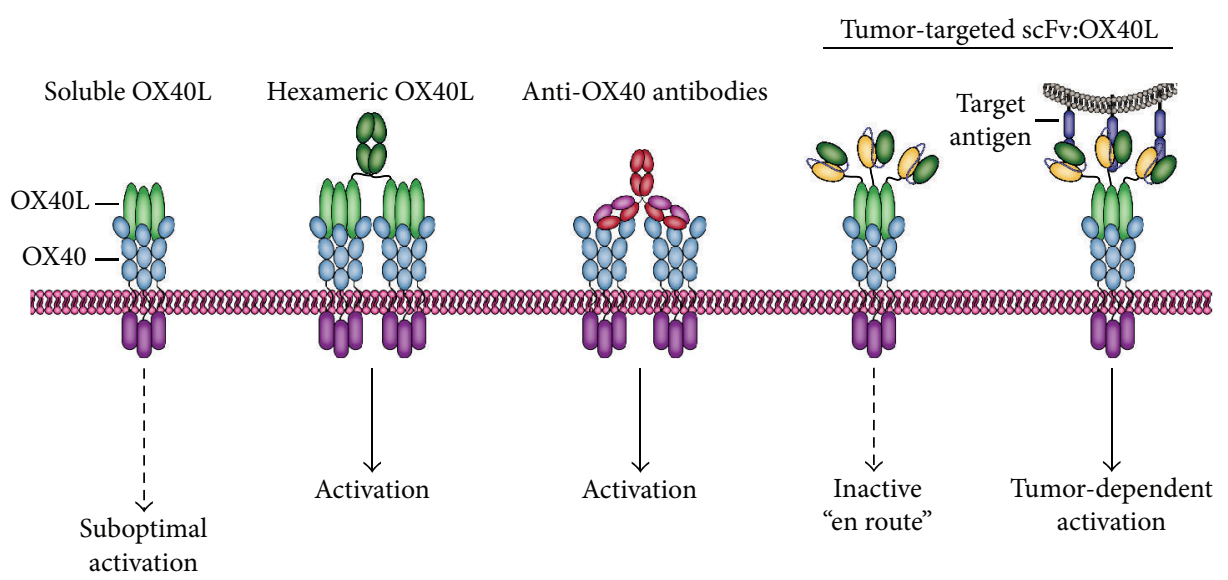

FIGURE 9: OX40L/OX40. Soluble OX40L can only suboptimally activate OX40 co-stimulatory signaling. Hexameric recombinant OX40L is fully capable of activating OX40-signaling like OX40 agonistic antibodies, with no dose-limiting toxicity of such an OX40 antibody in an early clinical trial. To increase tumor selectivity, sOX40L can be targeted to tumor cells using scFv:OX40L. The sOX40L domain will convert into membrane-like and fully signaling competent OX40L only upon selective binding to the targeted antigen.

(TCR) ligation on both activated CD4+ and CD8+ T-cells [221]. After 48-96h, the expression of OX40 on these activated T-cells is downregulated [221]. This temporal expression profile of OX40 corroborates with the required timing of therapeutic OX40 antibodies, which need to be given 1-2 days after antigenic stimulation [215]. During antigen recall, OX40 is rapidly expressed on memory T-cells within 1-4 h. Of note, OX40 is also constitutively expressed on T-regulatory $\left(\mathrm{T}_{\text {reg }}\right)$ cells in mice [166], but human $\mathrm{T}_{\text {reg }}$ express no or minimal OX40 although it can be up-regulated during inflammation.

\subsection{Triggering OX40L/OX40-Signaling for Cancer Therapy.} Since the initial report describing OX40 expression on tumor-infiltrating T-cells in melanoma and head and neck cancer patients [222], the therapeutic targeting of the OX40L/OX40 axis for cancer therapy has been pursued using agonistic OX40 antibodies or recombinant forms of soluble OX40L (e.g., OX40L:Fc) (Figure 9) [131, 223]. In various preclinical models of immunogenic tumors, such as CT26 colon cancer and MC303 sarcoma, OX40 antibody treatment was shown to eradicate tumor outgrowth [223, 224]. Based on these results a clinical trial was initiated with a murine antiOX40 monoclonal antibody (9B12). In this phase I trial of 30 patients a single bolus injection of 9B12 did not reach the maximum tolerated dose (MTD) and was associated with a relatively mild toxicity profile [225]. Importantly, patients receiving antiOX40 treatment had an increase in tumorspecific immune responses after therapy and had increased CD4+ and CD8+ T-cell proliferation. However, no objective clinical responses were detected, although some patients did experience tumor shrinkage. Of note, the detection of human antimouse antibody (HAMA) responses after single treatment highlights the need for development of a humanized antiOX40 antibody, which is currently being pursued. An alternative OX40 agonist is a recombinant hexameric human OX40L:Fc, comprising a trimerizing isoleucine zipper (ILZ) domain, which had superior biological activity as soluble therapeutic in vitro compared to antiOX40 antibody treatment [131], positioning OX40L-based therapeutics as viable alternative to agonistic OX40 antibodies.

However, in poorly immunogenic tumors single agent antiOX40 treatment does not provide adequate antitumor immunity, as a result of which combination of OX40 with other strategies has been pursued. In this respect, combination of OX40 with the $\mathrm{T}_{\text {reg }}$ depleting chemotherapeutic drug cyclophosphamide triggered a combined depletion of intratumoral regulatory T-cells and an influx of CD8+ CTL, which together yielded strong tumoricidal activity [226]. In line with this report, $\mathrm{T}_{\text {reg }}$ depletion was also observed in various other preclinical models with OX40 agonists [224, 227]. Synergistic tumoricidal activity was further identified in preclinical studies for combination of OX40 agonists with, for example, cytokines such as IL-2 [228], with tumor vaccination approaches [229], with adoptive T-cell transfer [189], and by combination with a $4-1 \mathrm{BB}$ agonist antibody [193].

9.2. Targeted OX40L-Based Cancer Immunotherapy. The previously described antibody-based OX40 agonist approaches can potentially activate the OX40L/OX40 ligand/receptor pair in a ubiquitous manner, which may translate into unanticipated off-target effects particularly upon combinatorial OX40-based therapeutic approaches. To achieve more selective tumor-specific activation of OX40 signaling on T-cells, the OX40L can be incorporated into an antibody fragmenttargeted approach. Specifically, soluble homotrimeric OX40L does not or only minimally induces OX40 signaling [230]. In contrast, hexameric OX40L proved to be fully capable of activating OX40 [230], a finding corroborated by the previously published co-stimulatory activity of the hexameric OX40L:Fc fusion protein $[131,230]$. Based on the previously described characteristics of the OX40/OX40L signaling pathway, OX40L seems particularly amenable to targeted delivery and activation. Indeed, antibody fragment-mediated 
delivery of sOX40L to the stroma marker FAP revealed potent OX40-signaling activity on targeted cells (Figure 9) [230]. In contrast, on FAP-negative cells this fusion protein remained essentially inactive. Thus, this novel fusion protein appears to fulfill the prerequisite of target-cell restricted activity and may be a useful agent for the selective enhancement of OX40-mediated T-cell co-stimulation in the tumor microenvironment.

\section{Conclusions}

As discussed in this review, both proapoptotic and costimulatory TNFL/TNFR ligand/receptor pairs hold considerable promise for immunotherapy of cancer, with various agonistic TNFR antibodies and recombinant soluble TNFLs poised for or undergoing clinical evaluation. Indeed, the host of ongoing preclinical studies and promising early clinical results suggests that targeting of the TNFL/TNFR axis will become part of clinical practice in the near future.

However, the ubiquitous activation of proapoptotic or co-stimulatory TNFR signaling can have severe side-effects, as evidenced by the early clinical experience with systemic TNF infusion as well as the recent experience with systemic agonistic 4-1BB antibody treatment. Thus, tumor-restricted activation is being pursued in order to fully capitalize on the therapeutic potential of this regulatory axis. In this respect, antibody fragment-based fusion proteins of the various TNFLs discussed here hold considerable promise. Such targeted TNFLs selectively bind to a tumor target antigen and, by virtue of the often reduced activity of soluble homotrimeric ligand, are relatively inactive "en route." However, once bound to the target antigen the ligand will acquire tumoricidal or co-stimulatory activity resembling that of the corresponding transmembrane ligands. For promiscuously active ligands such as TNF the incorporation into advanced prodrug strategies can further help to ensure strictly tumorlocalized unmasking of apoptotic activity. Thus, this targeting approach may make significant headway towards a "magic bullet" with maximum cancer-selective activity and minimal side effects.

Further, as evident from early clinical trials with TRAILreceptor as well as CD40 agonists, single agent treatment of patients will likely not yield sufficient clinical benefit. In order to achieve meaningful clinical responses, design of rational combinatorial strategies that ensure maximal synergistic tumoricidal activity and minimal toxicity are called for. Many such approaches have been initiated and are currently being evaluated in preclinical studies as well as early phase clinical trials. Of interest for proapoptotic ligands/receptors are combinations that converge on known antiapoptotic regulators of Death Receptor-mediated apoptosis. For co-stimulatory ligands/receptors, promising strategies include those that shift the immune-inhibitory tumor micro-environment towards an immune stimulatory tumor micro-environment by, for example, targeted depletion of regulatory T-cells and myeloid-derived suppressor cells.

Of note, an important issue that needs to be addressed for any new type of immunotherapy to enter clinical practice is the identification of appropriate patient stratification criteria. In this respect, $\mathrm{CD} 8+\mathrm{T}$-cell infiltration and $\mathrm{CD} 8+/ \mathrm{T}_{\text {reg }}$ ratios have prognostic value for patient survival and may also be used to identify patients likely to respond to immunotherapy [231]. The clinical activity of ipilimumab, for instance, correlated well with high baseline expression of FoxP3 and indoleamine 2,3-dioxygenase (IDO), an immunoregulatory enzyme that suppresses T-cell responses, and high numbers of tumor-infiltrating lymphocytes in a prospective phase II clinical trial and these markers may thus be of use in patient selection [232]. Thus, research in the upcoming years should focus on not only identifying integrated TNFL/TNFRbased combinatorial immunotherapeutics but also on the identification of appropriate patient selection criteria.
Abbreviations
TNF: $\quad$ Tumor necrosis factor
Fas: $\quad$ Fibroblast-associated cell-surface
FasL: $\quad$ Fibroblast-associated cell-surface ligand
TRAIL: TNF-related apoptosis-inducing ligand
TNFR1: TNF receptor 1
TNFR2: TNF receptor 2
TRAIL-R1: TRAIL receptor 1
TRAIL-R2: TRAIL receptor 2
DD: $\quad$ Death domain
LT $\alpha$ : Lymphotoxin alpha
scFv: $\quad$ Single chain fragment of variable regions
NF $\kappa$ B: $\quad$ Nuclear factor kappa B
FADD: $\quad$ Fas-associated death domain
TRADD: TNFR-associated via death domain
cIAP: Cellular inhibitor of apoptosis protein
TRAF2: $\quad$ TNF-receptor associated factor 2
cFLIP: Cellular FADD-like IL-1b-converting
enzyme inhibitory protein
FAP: $\quad$ Fibroblast activation protein
DcR3: $\quad$ Decoy receptor 3
DISC: Death inducing signaling complex
EGFR: Epidermal growth factor receptor
HER2: Human epidermal growth factor receptor 2
IL13R $\alpha 2: \quad$ Interleukin 13 receptor alpha 2
Bcl-2: B-cell lymphoma/leukemia 2 gene
Bcl-xL: B-cell leukemia xL.

\section{Conflict of Interests}

The author declares no conflict of interests.

\section{Acknowledgments}

The author gratefully acknowledges the helpful suggestions of Dr. Wijnand Helfrich and Dr. Marco de Bruyn and the help of Dr. Bruyn with the graphical design of the figures.

\section{References}

[1] D. W. Banner, A. D’Arcy, W. Janes et al., "Crystal structure of the soluble human $55 \mathrm{kd}$ TNF receptor-human TNF $\beta$ complex: 
implications for TNF receptor activation," Cell, vol. 73, no. 3, pp. 431-445, 1993.

[2] J. H. Naismith and S. R. Sprang, "Modularity in the TNFreceptor family," Trends in Biochemical Sciences, vol. 23, no. 2, pp. 74-79, 1998.

[3] M. E. Peter and P. H. Krammer, "The CD95(APO-1/Fas) DISC and beyond," Cell Death and Differentiation, vol. 10, no. 1, pp. 26-35, 2003.

[4] T. Kataoka, "The caspase-8 modulator c-FLIP," Critical Reviews in Immunology, vol. 25, no. 1, pp. 31-58, 2005.

[5] K. M. Boatright, M. Renatus, F. L. Scott et al., "A unified model for apical caspase activation," Molecular Cell, vol. 11, no. 2, pp. 529-541, 2003.

[6] M. de Bruyn, E. Bremer, and W. Helfrich, "Antibody-based fusion proteins to target death receptors in cancer," Cancer Letters, vol. 332, no. 2, pp. 175-183, 2011.

[7] M. Croft, "The role of TNF superfamily members in T-cell function and diseases," Nature Reviews Immunology, vol. 9, no. 4, pp. 271-285, 2009.

[8] H. Wajant, F. Henkler, and P. Scheurich, "The TNF-receptorassociated factor family: scaffold molecules for cytokine receptors, kinases and their regulators," Cellular Signalling, vol. 13, no. 6, pp. 389-400, 2001.

[9] J. Y. Chung, Y. C. Park, H. Ye, and H. Wu, "All TRAFs are not created equal: common and distinct molecular mechanisms of TRAF-mediated signal transduction," Journal of Cell Science, vol. 115, no. 4, pp. 679-688, 2002.

[10] R. A. Black, C. T. Rauch, C. J. Kozlosky et al., "A metalloproteinase disintegrin that releases tumour-necrosis factor- $\alpha$ from cells," Nature, vol. 385, no. 6618, pp. 729-733, 1997.

[11] O. Micheau and J. Tschopp, "Induction of TNF receptor Imediated apoptosis via two sequential signaling complexes," Cell, vol. 114, no. 2, pp. 181-190, 2003.

[12] S. Q. Zhang, A. Kovalenko, G. Cantarella, and D. Wallach, "Recruitment of the IKK signalosome to the p55 TNF receptor: RIP and A20 bind to NEMO (IKK $\gamma$ ) upon receptor stimulation," Immunity, vol. 12, no. 3, pp. 301-311, 2000.

[13] G. Chen and D. V. Goeddel, "TNF-R1 signaling: a beautiful pathway," Science, vol. 296, no. 5573, pp. 1634-1635, 2002.

[14] H. Wajant, K. Pfizenmaier, and P. Scheurich, "Tumor necrosis factor signaling," Cell Death and Differentiation, vol. 10, no. 1, pp. 45-65, 2003.

[15] L. J. Old, “Tumor necrosis factor," Scientific American, vol. 258, no. 5, pp. 59-69, 1988.

[16] B. J. Sugarman, B. B. Aggarwal, and P. E. Hass, "Recombinant human tumor necrosis factor- $\alpha$ : effects on proliferation of normal and transformed cells in vitro," Science, vol. 230, no. 4728, pp. 943-945, 1985.

[17] M. Kriegler, C. Perez, K. DeFay, I. Albert, and S. D. Lu, "A novel form of TNF/cachectin is a cell surface cytotoxic transmembrane protein: ramifications for the complex physiology of TNF," Cell, vol. 53, no. 1, pp. 45-53, 1988.

[18] M. Grell, E. Douni, H. Wajant et al., “The transmembrane form of tumor necrosis factor is the prime activating ligand of the 80 kDa tumor necrosis factor receptor," Cell, vol. 83, no. 5, pp. 793802, 1995.

[19] F. Balkwill, “Tumor necrosis factor or tumor promoting factor?” Cytokine and Growth Factor Reviews, vol. 13, no. 2, pp. 135-141, 2002.

[20] P. Selby, S. Hobbs, C. Viner et al., "Tumour necrosis factor in man: clinical and biological observations," British Journal of Cancer, vol. 56, no. 6, pp. 803-808, 1987.
[21] E. T. Creagan, J. S. Kovach, C. G. Moertel, S. Frytak, and L. K. Kvols, "A Phase I clinical trial of recombinant human tumor necrosis factor," Cancer, vol. 62, no. 12, pp. 2467-2471, 1988.

[22] A. M. M. Eggermont, J. H. W. de Wilt, and T. L. M. ten Hagen, "Current uses of isolated limb perfusion in the clinic and a model system for new strategies," Lancet Oncology, vol. 4, no. 7, pp. 429-437, 2003.

[23] J. Rothbarth, R. A. E. M. Tollenaar, J. H. M. Schellens et al., "Isolated hepatic perfusion for the treatment of colorectal metastases confined to the liver: recent trends and perspectives," European Journal of Cancer, vol. 40, no. 12, pp. 1812-1824, 2004.

[24] R. Fischer, O. Maier, M. Siegemund, H. Wajant, P. Scheurich, and K. Pfizenmaier, "A TNF receptor 2 selective agonist rescues human neurons from oxidative stress-induced cell death," PLoS ONE, vol. 6, no. 11, Article ID e27621, 2011.

[25] H. Wajant, J. Gerspach, and K. Pfizenmaier, "Tumor therapeutics by design: targeting and activation of death receptors," Cytokine and Growth Factor Reviews, vol. 16, no. 1, pp. 55-76, 2005.

[26] S. P. Cooke, R. B. Pedley, R. Boden, R. H. J. Begent, and K. A. Chester, "In vivo tumor delivery of a recombinant singlechain Fv: tumor necrosis factor: a fusion protein," Bioconjugate Chemistry, vol. 13, no. 1, pp. 7-15, 2002.

[27] C. Halin, V. Gafner, M. E. Villani et al., "Synergistic therapeutic effects of a tumor targeting antibody fragment, fused to interleukin 12 and to tumor necrosis factor $\alpha$," Cancer Research, vol. 63, no. 12, pp. 3202-3210, 2003.

[28] Y. Liu, L. H. Cheung, J. W. Marks, and M. G. Rosenblum, "Recombinant single-chain antibody fusion construct targeting human melanoma cells and containing tumor necrosis factor," International Journal of Cancer, vol. 108, no. 4, pp. 549-557, 2004.

[29] O. Christ, S. Matzku, C. Burger, and M. Zöller, "Interleukin 2antibody and tumor necrosis factor-antibody fusion proteins induce different antitumor immune responses in vivo," Clinical Cancer Research, vol. 7, no. 5, pp. 1385-1397, 2001.

[30] M. G. Rosenblum, S. A. Horn, and L. H. Cheung, "A novel recombinant fusion toxin targeting HER-2/NEU-overexpressing cells and containing human tumor necrosis factor," International Journal of Cancer, vol. 88, no. 2, pp. 267-273, 2000.

[31] F. Curnis, A. Sacchi, L. Borgna, F. Magni, A. Gasparri, and A. Corti, "Enhancement of tumor necrosis factor $\alpha$ antitumor immunotherapeutic properties by targeted delivery to aminopeptidase N (CD 13)," Nature Biotechnology, vol. 18, no. 11, pp. 1185-1190, 2000.

[32] S. Bauer, N. Adrian, B. Williamson et al., "Targeted bioactivity of membrane-anchored TNF by an antibody-derived TNF fusion protein," The Journal of Immunology, vol. 172, no. 6, pp. 39303939, 2004.

[33] S. Bauer, N. Adrian, E. Fischer et al., "Structure-activity profiles of ab-derived TNF fusion proteins," The Journal of Immunology, vol. 177, no. 4, pp. 2423-2430, 2006.

[34] J. Gerspach, J. Németh, S. Münkel, H. Wajant, and K. Pfizenmaier, "Target-selective activation of a TNF prodrug by urokinase-type plasminogen activator (uPA) mediated proteolytic processing at the cell surface," Cancer Immunology, Immunotherapy, vol. 55, no. 12, pp. 1590-1600, 2006.

[35] J. Gerspach, D. Müller, S. Münkel et al., "Restoration of membrane TNF-like activity by cell surface targeting and matrix metalloproteinase-mediated processing of a TNF prodrug," Cell Death and Differentiation, vol. 13, no. 2, pp. 273-284, 2006. 
[36] S. Fichtner-Feigl, M. Terabe, A. Kitani et al., "Restoration of tumor immunosurveillance via targeting of interleukin-13 receptor- $\alpha 2$," Cancer Research, vol. 68, no. 9, pp. 3467-3475, 2008.

[37] J.-H. Egberts, V. Cloosters, A. Noack et al., "Anti-tumor necrosis factor therapy inhibits pancreatic tumor growth and metastasis," Cancer Research, vol. 68, no. 5, pp. 1443-1450, 2008.

[38] B. C. Trauth, C. Klas, A. M. J. Peters et al., "Monoclonal antibody-mediated tumor regression by induction of apoptosis," Science, vol. 245, no. 4915, pp. 301-305, 1989.

[39] S. Yonehara, A. Ishii, and M. Yonehara, "A cell-killing monoclonal antibody (anti-Fas) to a cell surface antigen codownregulated with the receptor of tumor necrosis factor," Journal of Experimental Medicine, vol. 169, no. 5, pp. 1747-1756, 1989.

[40] F. K.-M. Chan, H. J. Chun, L. Zheng, R. M. Siegel, K. L. Bui, and M. J. Lenardo, "A domain in TNF receptors that mediates ligand-independent receptor assembty and signaling," Science, vol. 288 , no. 5475 , pp. 2351-2354, 2000.

[41] G. Papoff, P. Hausler, A. Eramo et al., "Identification and characterization of a ligand-independent oligomerization domain in the extracellular region of the CD95 death receptor," The Journal of Biological Chemistry, vol. 274, no. 53, pp. 38241-38250, 1999.

[42] R. M. Siegel, J. K. Frederiksen, D. A. Zacharias et al., "Fas preassociation required for apoptosis signaling and dominant inhibition by pathogenic mutations," Science, vol. 288, no. 5475, pp. 2354-2357, 2000.

[43] S. Kreuz, D. Siegmund, J.-J. Rumpf et al., "NF $\kappa$ B activation by Fas is mediated through FADD, caspase- 8 , and RIP and is inhibited by FLIP," The Journal of Cell Biology, vol. 166, no. 3, pp. 369-380, 2004.

[44] H. Wajant, K. Pfizenmaier, and P. Scheurich, "Non-apoptotic Fas signaling," Cytokine and Growth Factor Reviews, vol. 14, no. 1, pp. 53-66, 2003.

[45] R. M. Pitti, S. A. Marsters, D. A. Lawrence et al., "Genomic amplification of a decoy receptor for Fas ligand in lung and colon cancer," Nature, vol. 396, no. 6712, pp. 699-703, 1998.

[46] S. Hayashi, Y. Miura, T. Nishiyama et al., "Decoy receptor 3 expressed in rheumatoid synovial fibroblasts protects the cells against fas-induced apoptosis," Arthritis and Rheumatism, vol. 56, no. 4, pp. 1067-1075, 2007.

[47] D. Kägi, F. Vignaux, B. Ledermann et al., "Fas and perforin pathways as major mechanisms of T cell-mediated cytotoxicity," Science, vol. 265, no. 5171, pp. 528-530, 1994.

[48] B. Lowin, M. Hahne, C. Mattmann, and J. Tschopp, "Cytolytic T-cell cytotoxicity is mediated through perforin and Fas lytic pathways," Nature, vol. 370, no. 6491, pp. 650-652, 1994.

[49] J. H. Russell, B. Rush, C. Weaver, and R. Wang, "Mature T cells of autoimmune lpr/lpr mice have a defect in antigen-stimulated suicide," Proceedings of the National Academy of Sciences of the United States of America, vol. 90, no. 10, pp. 4409-4413, 1993.

[50] S. Nagata, "Apoptosis by death factor," Cell, vol. 88, no. 3, pp. 355-365, 1997.

[51] M. Tanaka, T. Suda, K. Haze et al., "Fas ligand in human serum," Nature Medicine, vol. 2, no. 3, pp. 317-322, 1996.

[52] H. Hashimoto, M. Tanaka, T. Suda et al., "Soluble Fas ligand in the joints of patients with rheumatoid arthritis and osteoarthritis," Arthritis \& Rheumatism, vol. 41, pp. 657-662, 1998.

[53] T. Suda, H. Hashimoto, M. Tanaka, T. Ochi, and S. Nagata, "Membrane Fas ligand kills human peripheral blood T lymphocytes, and soluble fas ligand blocks the killing," Journal of Experimental Medicine, vol. 186, no. 12, pp. 2045-2050, 1997.
[54] P. Schneider, N. Holler, J. L. Bodmer et al., "Conversion of membrane-bound Fas(CD95) ligand to its soluble form is associated with downregulation of its proapoptotic activity and loss of liver toxicity," Journal of Experimental Medicine, vol. 187, no. 8, pp. 1205-1213, 1998.

[55] J. Ogasawara, R. Watanabe-Fukunaga, M. Adachi et al., "Lethal effect of the anti-Fas antibody in mice," Nature, vol. 364, no. 6440, pp. 806-809, 1993.

[56] A. Rensing-Ehl, K. Frei, R. Flury et al., "Local Fas/APO-1 (CD95) ligand-mediated tumor cell killing in vivo," European Journal of Immunology, vol. 25, no. 8, pp. 2253-2258, 1995.

[57] N. Holler, A. Tardivel, M. Kovacsovics-Bankowski et al., "Two adjacent trimeric Fas ligands are required for Fas signaling and formation of a death-inducing signaling complex," Molecular and Cellular Biology, vol. 23, no. 4, pp. 1428-1440, 2003.

[58] P. Greaney, A. Nahimana, L. Lagopoulos et al., "A Fas agonist induces high levels of apoptosis in haematological malignancies," Leukemia Research, vol. 30, no. 4, pp. 415-426, 2006.

[59] S. Daburon, C. Devaud, P. Costet et al., "Functional characterization of a chimeric soluble Fas ligand polymer with in vivo anti-tumor activity," PLoS ONE, vol. 8, no. 1, Article ID e54000, 2013.

[60] K. Aoki, M. Kurooka, J.-J. Chen, J. Petryniak, E. G. Nabel, and G. J. Nabel, "Extracellular matrix interacts with soluble CD95L: retention and enhancement of cytoxicity," Nature Immunology, vol. 2, no. 4, pp. 333-337, 2001.

[61] D. Samel, D. Müller, J. Gerspach et al., "Generation of a FasLbased proapoptotic fusion protein devoid of systemic toxicity due to cell-surface antigen-restricted activation," The Journal of Biological Chemistry, vol. 278, no. 34, pp. 32077-32082, 2003.

[62] E. Bremer, B. Ten Cate, D. F. Samplonius, L. F. M. H. De Leij, and W. Helfrich, "CD7-restricted activation of Fas-mediated apoptosis: a novel therapeutic approach for acute T-cell leukemia," Blood, vol. 107, no. 7, pp. 2863-2870, 2006.

[63] E. Bremer, B. Ten Cate, D. F. Samplonius et al., "Superior activity of fusion protein scFvRit:sFasL over cotreatment with rituximab and fas agonists," Cancer Research, vol. 68, no. 2, pp. 597-604, 2008.

[64] E. Bremer, W. H. Abdulahad, M. de Bruyn et al., "Selective elimination of pathogenic synovial fluid T-cells from Rheumatoid Arthritis and Juvenile Idiopathic Arthritis by targeted activation of Fas-apoptotic signaling," Immunology Letters, vol. 138, no. 2, pp. 161-168, 2011.

[65] J. C. Byrd, S. Kitada, I. W. Flinn et al., "The mechanism of tumor cell clearance by rituximab in vivo in patients with B-cell chronic lymphocytic leukemia: evidence of caspase activation and apoptosis induction," Blood, vol. 99, no. 3, pp. 1038-1043, 2002.

[66] A. J. Stel, B. Ten Cate, S. Jacobs et al., "Fas receptor clustering and involvement of the death receptor pathway in rituximab-mediated apoptosis with concomitant sensitization of lymphoma B cells to Fas-induced apoptosis," The Journal of Immunology, vol. 178, no. 4, pp. 2287-2295, 2007.

[67] M. I. Vega, S. Huerta-Yepez, A. R. Jazirehi, H. Garban, and B. Bonavida, "Rituximab (chimeric anti-CD20) sensitizes B-NHL cell lines to Fas-induced apoptosis," Oncogene, vol. 24, no. 55, pp. 8114-8127, 2005.

[68] Y. Tone, M. Kawahara, D. Kawaguchi, H. Ueda, and T. Nagamune, "Death signalobody: inducing conditional cell death in response to a specific antigen," Human Gene Therapy Methods. In press. 
[69] I. Watermann, J. Gerspach, M. Lehne et al., "Activation of CD95L fusion protein prodrugs by tumor-associated proteases," Cell Death and Differentiation, vol. 14, no. 4, pp. 765-774, 2007.

[70] A. Almasan and A. Ashkenazi, "Apo2L/TRAIL: apoptosis signaling, biology, and potential for cancer therapy," Cytokine and Growth Factor Reviews, vol. 14, no. 3-4, pp. 337-348, 2003.

[71] L. Clancy, K. Mruk, K. Archer et al., "Preligand assembly domain-mediated ligand-independent association between TRAIL receptor 4 (TR4) and TR2 regulates TRAIL-induced apoptosis," Proceedings of the National Academy of Sciences of the United States of America, vol. 102, no. 50, pp. 18099-18104, 2005.

[72] D. Mérino, N. Lalaoui, A. Morizot, P. Schneider, E. Solary, and O. Micheau, "Differential inhibition of TRAIL-mediated DR5DISC formation by decoy receptors 1 and 2," Molecular and Cellular Biology, vol. 26, no. 19, pp. 7046-7055, 2006.

[73] F. Corallini, E. Rimondi, and P. Secchiero, "TRAIL and osteoprotegerin: a role in endothelial physiopathology?" Frontiers in Bioscience, vol. 13, no. 1, pp. 135-147, 2008.

[74] L. J. Robinson, C. W. Borysenko, and H. C. Blair, "Tumor necrosis factor family receptors regulating bone turnover: new observations in osteoblastic and osteoclastic cell lines," Annals of the New York Academy of Sciences, vol. 1116, pp. 432-443, 2007.

[75] E. Cretney, K. Takeda, H. Yagita, M. Glaccum, J. J. Peschon, and M. J. Smyth, "Increased susceptibility to tumor initiation and metastasis in TNF-related apoptosis-inducing ligand-deficient mice," The Journal of Immunology, vol. 168, no. 3, pp. 1356-1361, 2002.

[76] N. Kayagaki, N. Yamaguchi, M. Nakayama, E. Hiroshi, K. Okumura, and H. Yagita, "Type I interferons (IFNs) regulate tumor necrosis factor-related apoptosis-inducing ligand (TRAIL) expression on human T cells: a novel mechanism for the antitumor effects of type I IFNs," The Journal of Experimental Medicine, vol. 189, no. 9, pp. 1451-1460, 1999.

[77] L. M. Sedger, D. M. Shows, R. A. Blanton et al., "IFN- $\gamma$ mediates a novel antiviral activity through dynamic modulation of TRAIL and TRAIL receptor expression," The Journal of Immunology, vol. 163, no. 2, pp. 920-926, 1999.

[78] Q. Chen, B. Gong, A. S. Mahmoud-Ahmed et al., "Apo2L/ TRAIL and Bcl-2-related proteins regulate type I interferoninduced apoptosis in multiple myeloma," Blood, vol. 98, no. 7, pp. 2183-2192, 2001.

[79] C. Schmaltz, O. Alpdogan, B. J. Kappel et al., "T cells require TRAIL for optimal graft-versus-tumor activity," Nature Medicine, vol. 8, no. 12, pp. 1433-1437, 2002.

[80] A. Trauzold, D. Siegmund, B. Schniewind et al., "TRAIL promotes metastasis of human pancreatic ductal adenocarcinoma," Oncogene, vol. 25, no. 56, pp. 7434-7439, 2006.

[81] A. Ashkenazi, P. Holland, and S. G. Eckhardt, "Ligand-based targeting of apoptosis in cancer: the potential of recombinant human apoptosis ligand 2/tumor necrosis factor-related apoptosis-inducing ligand (rhApo2L/TRAIL)," The Journal of Clinical Oncology, vol. 26, no. 21, pp. 3621-3630, 2008.

[82] N. L. Fox, R. Humphreys, T. A. Luster, J. Klein, and G. Gallant, "Tumor necrosis factor-related apoptosis-inducing ligand (TRAIL) receptor-1 and receptor-2 agonists for cancer therapy," Expert Opinion on Biological Therapy, vol. 10, no. 1, pp. 1-18, 2010.

[83] A. Ashkenazi, "Targeting the extrinsic apoptosis pathway in cancer," Cytokine and Growth Factor Reviews, vol. 19, no. 3-4, pp. 325-331, 2008.
[84] A. Ashkenazi and R. S. Herbst, "To kill a tumor cell: the potential of proapoptotic receptor agonists," The Journal of Clinical Investigation, vol. 118, no. 6, pp. 1979-1990, 2008.

[85] D. Daniel, B. Yang, D. A. Lawrence et al., "Cooperation of the proapoptotic receptor agonist rhApo2L/TRAIL with the CD20 antibody rituximab against non-Hodgkin lymphoma xenografts," Blood, vol. 110, no. 12, pp. 4037-4046, 2007.

[86] S. Maddipatla, F. J. Hernandez-Ilizaliturri, J. Knight, and M. S. Czuczman, "Augmented antitumor activity against B-cell lymphoma by a combination of monoclonal antibodies targeting TRAIL-R1 and CD20," Clinical Cancer Research, vol. 13, no. 15, pp. 4556-4564, 2007.

[87] J. C. Soria, Z. Márk, P. Zatloukal et al., "Randomized phase II study of dulanermin in combination with paclitaxel, carboplatin, and bevacizumab in advanced non-small-cell lung cancer," The Journal of Clinical Oncology, vol. 29, no. 33, pp. 4442-4451, 2011.

[88] M. Croft, C. A. Benedict, and C. F. Ware, "Clinical targeting of the TNF and TNFR superfamilies," Nature Reviews Drug Discovery, vol. 12, pp. 147-168, 2013.

[89] Y. Li, H. Wang, Z. Wang et al., "Inducible resistance of tumor cells to tumor necrosis factor-related apoptosis-inducing ligand receptor 2-mediated apoptosis by generation of a blockade at the death domain function," Cancer Research, vol. 66, no. 17, pp. 8520-8528, 2006.

[90] F. Mühlenbeck, P. Schneider, J.-L. Bodmer et al., "The tumor necrosis factor-related apoptosis-inducing ligand receptors TRAIL-R1 and TRAIL-R2 have distinct cross-linking requirements for initiation of apoptosis and are non-redundant in JNK activation," The Journal of Biological Chemistry, vol. 275, no. 41, pp. 32208-32213, 2000.

[91] S. K. Kelley, L. A. Harris, D. Xie et al., "Preclinical studies to predict the disposition of Apo2L/tumor necrosis factorrelated apoptosis-inducing ligand in humans: characterization of in vivo efficacy, pharmacokinetics, and safety," Journal of Pharmacology and Experimental Therapeutics, vol. 299, no. 1, pp. 31-38, 2001.

[92] E. Bremer, M. De Bruyn, D. F. Samplonius et al., "Targeted delivery of a designed sTRAIL mutant results in superior apoptotic activity towards EGFR-positive tumor cells," Journal of Molecular Medicine, vol. 86, no. 8, pp. 909-924, 2008.

[93] E. Bremer, D. F. Samplonius, M. Peipp et al., "Target cellrestricted apoptosis induction of acute leukemic $\mathrm{T}$ cells by a recombinant tumor necrosis factor-related apoptosis-inducing ligand fusion protein with specificity for human CD7," Cancer Research, vol. 65, no. 8, pp. 3380-3388, 2005.

[94] E. Bremer, D. F. Samplonius, L. Van Genne et al., "Simultaneous inhibition of Epidermal Growth Factor Receptor (EGFR) signaling and enhanced activation of tumor necrosis factor-related apoptosis-inducing ligand (TRAIL) receptor-mediated apoptosis induction by an scFv:sTRAIL fusion protein with specificity for human EGFR," The Journal of Biological Chemistry, vol. 280, no. 11, pp. 10025-10033, 2005.

[95] J. Stieglmaier, E. Bremer, C. Kellner et al., "Selective induction of apoptosis in leukemic B-lymphoid cells by a CD19-specific TRAIL fusion protein," Cancer Immunology, Immunotherapy, vol. 57, no. 2, pp. 233-246, 2008.

[96] E. Bremer, G. M. van Dam, M. de Bruyn et al., "Potent systemic anticancer activity of adenovirally expressed EGFR-selective TRAIL fusion protein," Molecular Therapy, vol. 16, no. 12, pp. 1919-1926, 2008. 
[97] H. Wajant, D. Moosmayer, T. Wüest et al., "Differential activation of TRAIL-R1 and -2 by soluble and membrane TRAIL allows selective surface antigen-directed activation of TRAILR2 by a soluble TRAIL derivative," Oncogene, vol. 20, no. 30, pp. 4101-4106, 2001.

[98] E. Bremer, J. Kuijlen, D. Samplonius, H. Walczak, L. De Leij, and W. Helfrich, "Target cell-restricted and -enhanced apoptosis induction by a scFv:sTRAIL fusion protein with specificity for the pancarcinoma-associated antigen EGP2," International Journal of Cancer, vol. 109, no. 2, pp. 281-290, 2004.

[99] E. Bremer, D. Samplonius, B.-J. Kroesen, L. Van Genne, L. De Leij, and W. Helfrich, "Exceptionally potent anti-tumor bystander activity of an scFv:sTRAIL fusion protein with specificity for EGP2 toward target antigen-negative tumor cells," Neoplasia, vol. 6, no. 5, pp. 636-645, 2004.

[100] M. de Bruyn, A. A. Rybczynska, Y. Wei et al., "Melanomaassociated Chondroitin Sulfate Proteoglycan (MCSP)-targeted delivery of soluble TRAIL potently inhibits melanoma outgrowth in vitro and in vivo," Molecular Cancer, vol. 9, article 301, 2010.

[101] J. Yang, M. A. Price, Y. L. Gui et al., "Melanoma proteoglycan modifies gene expression to stimulate tumor cell motility, growth, and epithelial-to-mesenchymal transition," Cancer Research, vol. 69, no. 19, pp. 7538-7547, 2009.

[102] J. Yang, M. A. Price, C. L. Neudauer et al., "Melanoma chondroitin sulfate proteoglycan enhances FAK and ERK activation by distinct mechanisms," The Journal of Cell Biology, vol. 165, no. 6, pp. 881-891, 2004.

[103] M. De Bruyn, Y. Wei, V. R. Wiersma et al., "Cell surface delivery of TRAIL strongly augments the tumoricidal activity of T cells," Clinical Cancer Research, vol. 17, no. 17, pp. 5626-5637, 2011.

[104] J. B. Sunwoo, Z. Chen, G. Dong et al., "Novel proteasome inhibitor PS-341 inhibits activation of nuclear factor- $\kappa \mathrm{B}$, cell survival, tumor growth, and angiogenesis in squamous cell carcinoma," Clinical Cancer Research, vol. 7, no. 5, pp. 1419-1428, 2001.

[105] G. J. Gores and S. H. Kaufmann, "Is TRAIL hepatotoxic?" Hepatology, vol. 34, no. 1, pp. 3-6, 2001.

[106] R. Koschny, T. M. Ganten, J. Sykora et al., “TRAIL/bortezomib cotreatment is potentially hepatotoxic but induces cancerspecific apoptosis within a therapeutic window," Hepatology, vol. 45, no. 3, pp. 649-658, 2007.

[107] K. Wahl, M. Siegemund, F. Lehner et al., "Increased apoptosis induction in hepatocellular carcinoma by a novel tumortargeted TRAIL fusion protein combined with bortezomib," Hepatology, vol. 57, pp. 625-636, 2013.

[108] B. Schneider, S. Münkel, A. Krippner-Heidenreich et al., "Potent antitumoral activity of TRAIL through generation of tumortargeted single-chain fusion proteins," Cell Death and Disease, vol. 1, no. 8, article e68, 2010.

[109] M. Siegemund, N. Pollak, O. Seifert et al., "Superior antitumoral activity of dimerized targeted single-chain TRAIL fusion proteins under retention of tumor selectivity," Cell Death and Disease, vol. 3, no. 3, p. e295, 2012.

[110] B. A. Inman, X. Frigola, H. Dong, and E. D. Kwon, "Costimulation, coinhibition and cancer," Current Cancer Drug Targets, vol. 7, no. 1, pp. 15-30, 2007.

[111] E. Sato, S. H. Olson, J. Ahn et al., "Intraepithelial CD8 ${ }^{+}$tumorinfiltrating lymphocytes and a high $\mathrm{CD}^{+} /$regulatory $\mathrm{T}$ cell ratio are associated with favorable prognosis in ovarian cancer," Proceedings of the National Academy of Sciences of the United States of America, vol. 102, no. 51, pp. 18538-18543, 2005.
[112] F. S. Hodi, S. J. O’Day, D. F. McDermott et al., "Improved survival with ipilimumab in patients with metastatic melanoma," The New England Journal of Medicine, vol. 363, no. 8, pp. 711723, 2010.

[113] S. L. Topalian, F. S. Hodi, J. R. Brahmer et al., "Safety, activity, and immune correlates of anti-PD-1 antibody in cancer," The New England Journal of Medicine, vol. 366, pp. 2443-2454, 2012.

[114] J. R. Brahmer, S. S. Tykodi, L. Q. Chow et al., "Safety and activity of anti-PD-L1 antibody in patients with advanced cancer," The New England Journal of Medicine, vol. 366, pp. 2455-2465, 2012.

[115] D. Schrama, H. Voigt, A. O. Eggert et al., "Immunological tumor destruction in a murine melanoma model by targeted LT $\alpha$ independent of secondary lymphoid tissue," Cancer Immunology, Immunotherapy, vol. 57, no. 1, pp. 85-95, 2008.

[116] D. Schrama, P. Thor Straten, W. H. Fischer et al., "Targeting of lymphotoxin- $\alpha$ to the tumor elicits an efficient immune response associated with induction of peripheral lymphoid-like tissue," Immunity, vol. 14, no. 2, pp. 111-121, 2001.

[117] D. S. Vinay and B. S. Kwon, "TNF superfamily: costimulation and clinical applications," Cell Biology International, vol. 33, no. 4, pp. 453-465, 2009.

[118] P. A. Ascierto, E. Simeone, M. Sznol, Y. X. Fu, and I. Melero, "Clinical experiences with anti-CD137 and anti-PD1 therapeutic antibodies," Seminars in Oncology, vol. 37, no. 5, pp. 508-516, 2010.

[119] S. Pesonen, I. Diaconu, L. Kangasniemi et al., "Oncolytic immunotherapy of advanced solid tumors with a CD40Lexpressing replicating adenovirus: assessment of safety and immunologic responses in patients," Cancer Research, vol. 72, no. 7, pp. 1621-1631, 2012.

[120] J. C. Byrd, T. J. Kipps, I. W. Flinn et al., "Phase I study of the anti-CD40 humanized monoclonal antibody lucatumumab (HCD122) in relapsed chronic lymphocytic leukemia," Leukemia \& Lymphoma, vol. 53, no. 11, pp. 2136-2142, 2012.

[121] J. F. Gauchat, J. P. Aubry, G. Mazzei et al., "Human CD40ligand: Molecular cloning, cellular distribution and regulation of expression by factors controlling IgE production," FEBS Letters, vol. 315, no. 3, pp. 259-266, 1993.

[122] L. Biancone, V. Cantaluppi, and G. Camussi, "CD40-CD154 interaction in experimental and human disease (Review)," International Journal of Molecular Medicine, vol. 3, no. 4, pp. 343-353, 1999.

[123] C. Van Kooten and J. Banchereau, "Functions of CD40 on B cells, dendritic cells and other cells," Current Opinion in Immunology, vol. 9, no. 3, pp. 330-337, 1997.

[124] J. E. Freedman, "CD40-CD40L and platelet function: beyond hemostasis," Circulation Research, vol. 92, no. 9, pp. 944-946, 2003.

[125] A. Khong, D. J. Nelson, A. K. Nowak, R. A. Lake, and B. W. Robinson, "The use of agonistic anti-CD40 therapy in treatments for cancer," International Reviews of Immunology, vol. 31, no. 4, pp. 246-266, 2012.

[126] A. L. Marzo, B. F. Kinnear, R. A. Lake et al., "Tumor-specific $\mathrm{CD}^{+} \mathrm{T}$ cells have a major "post-licensing" role in CTL mediated anti-tumor immunity," The Journal of Immunology, vol. 165, no. 11, pp. 6047-6055, 2000.

[127] J. P. Ridge, F. Di Rosa, and P. Matzinger, "A conditioned dendritic cell can be a temporal bridge between a $\mathrm{CD} 4^{+} \mathrm{T}$ helper and a T-killer cell," Nature, vol. 393, no. 6684, pp. 474478, 1998. 
[128] T. B. Hunter, M. Alsarraj, R. P. Gladue, V. Bedian, and S. J. Antonia, "An agonist antibody specific for CD40 induces dendritic cell maturation and promotes autologous anti-tumour T-cell responses in an in vitro mixed autologous tumour cell/lymph node cell model," Scandinavian Journal of Immunology, vol. 65, no. 5, pp. 479-486, 2007.

[129] C. J. M. Melief, "Cancer Immunotherapy by Dendritic Cells," Immunity, vol. 29, no. 3, pp. 372-383, 2008.

[130] R. R. French, H. T. C. Chan, A. L. Tutt, and M. J. Glennie, “CD40 antibody evokes a cytotoxic T-cell response that eradicates lymphoma and bypasses T-cell help," Nature Medicine, vol. 5, no. 5, pp. 548-553, 1999.

[131] N. P. Morris, C. Peters, R. Montler et al., "Development and characterization of recombinant human Fc:OX40L fusion protein linked via a coiled-coil trimerization domain," Molecular Immunology, vol. 44, no. 12, pp. 3112-3121, 2007.

[132] S. M. Todryk, A. L. Tutt, M. H. A. Green et al., "CD40 ligation for immunotherapy of solid tumours," Journal of Immunological Methods, vol. 248, no. 1-2, pp. 139-147, 2001.

[133] R. H. Vonderheide, K. T. Flaherty, M. Khalil et al., "Clinical activity and immune modulation in cancer patients treated with CP-870,893, a novel CD40 agonist monoclonal antibody," The Journal of Clinical Oncology, vol. 25, no. 7, pp. 876-883, 2007.

[134] J. Rüter, S. J. Antonia, H. A. Burris III, R. D. Huhn, and R. H. Vonderheide, "Immune modulation with weekly dosing of an agonist CD40 antibody in a phase I study of patients with advanced solid tumors," Cancer Biology and Therapy, vol. 10, no. 10, pp. 983-993, 2010.

[135] G. L. Beatty, E. G. Chiorean, M. P. Fishman et al., "CD40 agonists alter tumor stroma and show efficacy against pancreatic carcinoma in mice and humans," Science, vol. 331, no. 6024, pp. 1612-1616, 2011.

[136] S. He, H. Zhao, M. Fei et al., "Expression of the co-signaling molecules CD40-CD40L and their growth inhibitory effect on pancreatic cancer in vitro," Oncology Reports, vol. 28, pp. 262268, 2012.

[137] Y. Zhou, J. He, L.-T. Gou et al., "Expression of CD40 and growthinhibitory activity of CD40 agonist in ovarian carcinoma cells," Cancer Immunology, Immunotherapy, vol. 61, no. 10, pp. 17351743, 2012.

[138] A. L. White, H. T. C. Chan, A. Roghanian et al., "Interaction with Fc $\gamma$ RIIB is critical for the agonistic activity of anti-CD40 monoclonal antibody," The Journal of Immunology, vol. 187, no. 4, pp. 1754-1763, 2011.

[139] A. Wyzgol, N. Müller, A. Fick et al., "Trimer stabilization, oligomerization, and antibody-mediated cell surface immobilization improve the activity of soluble trimers of CD27L, CD40L, 41BBL, and glucocorticoid-induced TNF receptor ligand," The Journal of Immunology, vol. 183, no. 3, pp. 1851-1861, 2009.

[140] I. Miconnet and G. Pantaleo, "A soluble hexameric form of CD40 ligand activates human dendritic cells and augments memory T cell response," Vaccine, vol. 26, no. 32, pp. 4006-4014, 2008.

[141] L. Haswell, M. Glennie, and A. Al-Shamkhani, "Analysis of the oligomeric requirement for signaling by CD40 using soluble multimeric forms of its ligand, CD154," European Journal of Immunology, vol. 31, pp. 3094-3100, 2001.

[142] S. K. Kanagavelu, V. Snarsky, J. M. Termini et al., "Soluble multitrimeric TNF superfamily ligand adjuvants enhance immune responses to a HIV-1 Gag DNA vaccine," Vaccine, vol. 30, no. 4, pp. 691-702, 2012.
[143] G. Ullenhag and A. S. Loskog, "AdCD40L_crossing the valley of death?" International Reviews of Immunology, vol. 31, no. 4, pp. 289-298, 2012.

[144] W. G. Wierda, M. J. Cantwell, S. J. Woods, L. Z. Rassenti, C. E. Prussak, and T. J. Kipps, "CD40-ligand (CD154) gene therapy for chronic lymphocytic leukemia," Blood, vol. 96, no. 9, pp. 2917-2924, 2000.

[145] E. Biagi, R. Rousseau, E. Yvon et al., "Responses to human CD40 ligand/human interleukin-2 autologous cell vaccine in patients with B-cell chronic lymphocytic leukemia," Clinical Cancer Research, vol. 11, no. 19 I, pp. 6916-6923, 2005.

[146] R. F. Rousseau, E. Biagi, A. Dutour et al., "Immunotherapy of high-risk acute leukemia with a recipient (autologous) vaccine expressing transgenic human CD40L and IL-2 after chemotherapy and allogeneic stem cell transplantation," Blood, vol. 107, no. 4, pp. 1332-1341, 2006.

[147] I. Houtenbos, S. Santegoets, T. M. Westers et al., "The novel bispecific diabody $\alpha \mathrm{cD} 40 / \alpha \mathrm{CD} 28$ strengthens leukaemic dendritic cell-induced T-cell reactivity," British Journal of Haematology, vol. 142, no. 2, pp. 273-283, 2008.

[148] J.-M. Wu, X.-F. Lin, Z.-M. Huang, and J. S. Wu, "Construction of the HBV S-ecdCD40L fusion gene and effects of HBV SecdCD40L modification on function of dendritic cells," Journal of Viral Hepatitis, vol. 18, no. 10, pp. e461-e467, 2011.

[149] R. S. Kornbluth, M. Stempniak, and G. W. Stone, "Design of CD40 agonists and their use in growing B cells for cancer immunotherapy," International Reviews of Immunology, vol. 31, no. 4, pp. 279-288, 2012.

[150] R. Lapointe, A. Bellemare-Pelletier, F. Housseau, J. Thibodeau, and P. Hwu, "CD40-stimulated B lymphocytes pulsed with tumor antigens are effective antigen-presenting cells that can generate specific T cells," Cancer Research, vol. 63, no. 11, pp. 2836-2843, 2003.

[151] M. F. Fransen, M. Sluijter, H. Morreau, R. Arens, and C. J. M. Melief, "Local activation of CD8 T cells and systemic tumor eradication without toxicity via slow release and local delivery of agonistic CD40 antibody," Clinical Cancer Research, vol. 17, no. 8, pp. 2270-2280, 2011.

[152] E. M. Gomes, M. S. Rodrigues, A. P. Phadke et al., "Antitumor activity of an oncolytic adenoviral-CD40 ligand (CD154) transgene construct in human breast cancer cells," Clinical Cancer Research, vol. 15, no. 4, pp. 1317-1325, 2009.

[153] M. S. Fernandes, E. M. Gomes, L. D. Butcher et al., "Growth inhibition of human multiple myeloma cells by an oncolytic adenovirus carrying the CD40 ligand transgene," Clinical Cancer Research, vol. 15, no. 15, pp. 4847-4856, 2009.

[154] J. Schlom, C. Jochems, J. L. Gulley, and J. Huang, "The role of soluble CD40L in immunosuppression," Oncoimmunology, vol. 2, no. 1, Article ID e22546, 2013.

[155] J. Huang, C. Jochems, T. Talaie et al., "Elevated serum soluble CD40 ligand in cancer patients may play an immunosuppressive role," Blood, vol. 120, pp. 3030-3038, 2012.

[156] R. G. Goodwin, M. R. Alderson, C. A. Smith et al., "Molecular and biological characterization of a ligand for CD27 defines a new family of cytokines with homology to tumor necrosis factor," Cell, vol. 73, no. 3, pp. 447-456, 1993.

[157] M. R. Bowman, M. A. V. Crimmins, J. Yetz-Aldape, R. Kriz, K. Kelleher, and S. Herrmann, "The cloning of CD70 and its identification as the ligand for CD27," The Journal of Immunology, vol. 152, no. 4, pp. 1756-1761, 1994. 
[158] J. Borst, J. Hendriks, and Y. Xiao, "CD27 and CD70 in T cell and B cell activation," Current Opinion in Immunology, vol. 17, no. 3, pp. 275-281, 2005.

[159] D. Camerini, G. Walz, W. A. M. Loenen, J. Borst, and B. Seed, "The T cell activation antigen CD27 is a member of the nerve growth factor/tumor necrosis factor receptor gene family," The Journal of Immunology, vol. 147, no. 9, pp. 3165-3169, 1991.

[160] R. Q. Hintzen, R. A. W. Van Lier, K. C. Kuijpers et al., "Elevated levels of a soluble form of the T cell activation antigen CD27 in cerebrospinal fluid of multiple sclerosis patients," Journal of Neuroimmunology, vol. 35, no. 1-3, pp. 211-217, 1991.

[161] R. Arens, K. Schepers, M. A. Nolte et al., "Tumor rejection induced by CD70-mediated quantitative and qualitative effects on effector $\mathrm{CD}^{+}{ }^{+} \mathrm{T}$ cell formation," Journal of Experimental Medicine, vol. 199, no. 11, pp. 1595-1605, 2004.

[162] T. F. Rowley and A. Al-Shamkhani, "Stimulation by soluble CD70 promotes strong primary and secondary $\mathrm{CD}^{+}$cytotoxic T Cell responses in vivo," The Journal of Immunology, vol. 172, no. 10, pp. 6039-6046, 2004.

[163] S. M. A. Lens, P. A. Baars, B. Hooibrink, M. H. J. Van Oers, and R. A. W. Van Lier, "Antigen-presenting cell-derived signals determine expression levels of CD70 on primed T cells," Immunology, vol. 90, no. 1, pp. 38-45, 1997.

[164] R. De Jong, W. A. M. Loenen, M. Brouwer et al., "Regulation of expression of CD27, A T cell-specific member of a novel family of membrane receptors," The Journal of Immunology, vol. 146, no. 8, pp. 2488-2494, 1991.

[165] R. Q. Hintzen, R. De Jong, S. M. A. Lens, M. Brouwer, P. Baars, and R. A. W. Van Lier, "Regulation of CD27 expression on subsets of mature T-lymphocytes," The Journal of Immunology, vol. 151, no. 5, pp. 2426-2435, 1993.

[166] T. H. Watts, "TNF/TNFR family members in costimulation of T cell responses," Annual Review of Immunology, vol. 23, pp. 2368, 2005.

[167] J. Hendriks, L. A. Gravestein, K. Tesselaar, R. A. W. Van Lier, T. N. M. Schumacher, and J. Borst, "CD27 is required for generation and long-term maintenance of T cell immunity," Nature Immunology, vol. 1, no. 5, pp. 433-440, 2000.

[168] M. Hashimoto-Okada, T. Kitawaki, N. Kadowaki et al., "The CD70-CD27 interaction during the stimulation with dendritic cells promotes naive $\mathrm{CD}^{+} \mathrm{T}$ cells to develop into $\mathrm{T}$ cells producing a broad array of immunostimulatory cytokines in humans," International Immunology, vol. 21, no. 8, pp. 891-904, 2009.

[169] I. S. Grewal, "CD70 as a therapeutic target in human malignancies," Expert Opinion on Therapeutic Targets, vol. 12, no. 3, pp. 341-351, 2008.

[170] J. A. McEarchern, E. Oflazoglu, L. Francisco et al., "Engineered anti-CD70 antibody with multiple effector functions exhibits in vitro and in vivo antitumor activities," Blood, vol. 109, no. 3, pp. 1185-1192, 2007.

[171] D. J. Roberts, N. A. Franklin, L. M. Kingeter et al., "Control of established melanoma by $\mathrm{cd} 27$ stimulation is associated with enhanced effector function and persistence, and reduced PD1 expression of tumor infiltrating $\mathrm{CD}^{+} \mathrm{T}$ cells," The Journal of Immunotherapy, vol. 33, no. 8, pp. 769-779, 2010.

[172] R. R. French, V. Y. Taraban, G. R. Crowther et al., "Eradication of lymphoma by CD8 T cells following anti-CD40 monoclonal antibody therapy is critically dependent on CD27 costimulation," Blood, vol. 109, no. 11, pp. 4810-4815, 2007.
[173] C. Claus, C. Riether, C. Schürch et al., "CD27 signaling increases the frequency of regulatory T cells and promotes tumor growth," Cancer Research, vol. 72, pp. 3664-3676, 2012.

[174] J. Diegmann, K. Junker, I. F. Loncarevic, S. Michel, B. Schimmel, and F. Von Eggeling, "Immune escape for renal cell carcinoma: CD70 mediates apoptosis in lymphocytes," Neoplasia, vol. 8, no. 11, pp. 933-938, 2006.

[175] L. M. Snell, G. H. Y. Lin, A. J. McPherson, T. J. Moraes, and T. H. Watts, "T-cell intrinsic effects of GITR and 4-1BB during viral infection and cancer immunotherapy," Immunological Reviews, vol. 244, no. 1, pp. 197-217, 2011.

[176] A. Schoenbrunn, M. Frentsch, S. Kohler et al., "A converse 4$1 \mathrm{BB}$ and $\mathrm{CD} 40$ ligand expression pattern delineates Activated regulatory $\mathrm{T}$ cells, $\left(\mathrm{T}_{\text {reg }}\right)$ and conventional $\mathrm{T}$ cells enabling direct isolation of alloantigen-reactive natural Foxp $3^{+} \mathrm{T}_{\text {reg, }}$, The Journal of Immunology, vol. 189, pp. 5985-5994, 2012.

[177] R. H. Arch and C. B. Thompson, "4-1BB and Ox40 are members of a tumor necrosis factor (TNF)-nerve growth factor receptor subfamily that bind TNF receptor-associated factors and activate nuclear factor $\kappa \mathrm{B}$, " Molecular and Cellular Biology, vol. 18, no. 1, pp. 558-565, 1998.

[178] L. Stärck, C. Scholz, B. Dörken, and P. T. Daniel, "Costimulation by CD137/4-1BB inhibits $\mathrm{T}$ cell apoptosis and induces $\mathrm{Bcl}-\mathrm{xL}$ and c-FLIPshort via phosphatidylinositol 3-kinase and AKT/protein kinase B," European Journal of Immunology, vol. 35, no. 4, pp. 1257-1266, 2005.

[179] H. W. Lee, S. J. Park, B. K. Choi, H. H. Kim, K. O. Nam, and B. S. Kwon, "4-1BB promotes the survival of $\mathrm{CD} 8^{+} \mathrm{T}$ lymphocytes by increasing expression of Bcl-xL and Bfl-1," The Journal of Immunology, vol. 169, no. 9, pp. 4882-4888, 2002.

[180] I. Gramaglia, D. Cooper, K. T. Miner, B. S. Kwon, and M. Croft, "Co-stimulation of antigen-specific CD4 T cells by 4-1BB ligand," European Journal of Immunology, vol. 30, pp. 392-402, 2000 .

[181] J. L. Cannons, P. Lau, B. Ghumman et al., “4-1BB ligand induces cell division, sustains survival, and enhances effector function of CD4 and CD8 T cells with similar efficacy," The Journal of Immunology, vol. 167, no. 3, pp. 1313-1324, 2001.

[182] W. W. Shuford, K. Klussman, D. D. Tritchler et al., "4-1BB costimulatory signals preferentially induce $\mathrm{CD}^{+} \mathrm{T}$ cell proliferation and lead to the amplification in vivo of cytotoxic $\mathrm{T}$ cell responses," Journal of Experimental Medicine, vol. 186, no. 1, pp. 47-55, 1997.

[183] C. Takahashi, R. S. Mittler, and A. T. Vella, "Cutting edge: 4$1 \mathrm{BB}$ is a bona fide CD8 T cell survival signal," The Journal of Immunology, vol. 162, no. 9, pp. 5037-5040, 1999.

[184] G. Pulle, M. Vidric, and T. H. Watts, "IL-15-dependent induction of 4-1BB promotes antigen-independent CD8 memory T cell survival," The Journal of Immunology, vol. 176, no. 5, pp. 2739-2748, 2006.

[185] J. C. Hurtado, Y.-J. Kim, and B. S. Kwon, "Signals through 4-1BB are costimulatory to previously activated splenic T cells and inhibit activation-induced cell death," The Journal of Immunology, vol. 158, no. 6, pp. 2600-2609, 1997.

[186] E. M. Bertram, W. Dawicki, B. Sedgmen, J. L. Bramson, D. H. Lynch, and T. H. Watts, "A switch in costimulation from CD28 to $4-1 \mathrm{BB}$ during primary versus secondary CD8 $\mathrm{T}$ cell response to influenza in vivo," The Journal of Immunology, vol. 172, no. 2, pp. 981-988, 2004.

[187] J. T. Tan, J. K. Whitmire, R. Ahmed, T. C. Pearson, and C. P. Larsen, "4-1BB ligand, a member of the TNF family, is 
important for the generation of antiviral CD8 T cell responses," The Journal of Immunology, vol. 163, no. 9, pp. 4859-4868, 1999.

[188] D. J. Shedlock, J. K. Whitmire, J. Tan, A. S. MacDonald, R. Ahmed, and H. Shen, "Role of CD4 T cell help and costimulation in CD8 $\mathrm{T}$ cell responses during Listeria monocytogenes infection," The Journal of Immunology, vol. 170, no. 4, pp. 20532063, 2003.

[189] R. Houot and R. Levy, "T-cell modulation combined with intratumoral $\mathrm{CpG}$ cures lymphoma in a mouse model without the need for chemotherapy," Blood, vol. 113, no. 15, pp. 35463552, 2009.

[190] O. Murillo, A. Arina, S. Hervas-Stubbs et al., "Therapeutic antitumor efficacy of anti-CD137 agonistic monoclonal antibody in mouse models of myeloma," Clinical Cancer Research, vol. 14, no. 21, pp. 6895-6906, 2008.

[191] I. Melero, W. W. Shuford, S. A. Newby et al., "Monoclonal antibodies against the 4 -1BB T-cell activation molecule eradicate established tumors," Nature Medicine, vol. 3, no. 6, pp. 682-685, 1997.

[192] L. Niu, S. Strahotin, B. Hewes et al., "Cytokine-mediated disruption of lymphocyte trafficking, hemopoiesis, and induction of lymphopenia, anemia, and thrombocytopenia in anti-CD137treated mice," The Journal of Immunology, vol. 178, no. 7, pp. 4194-4213, 2007.

[193] S. J. Lee, L. Myers, G. Muralimohan et al., "4-1BB and OX40 dual costimulation synergistically stimulate primary specific CD8 T cells for robust effector function," The Journal of Immunology, vol. 173, no. 5, pp. 3002-3012, 2004.

[194] R. K. Sharma, A. K. Srivastava, E. S. Yolcu et al., "SA-4-1BBL as the immunomodulatory component of a HPV-16 E7 protein based vaccine shows robust therapeutic efficacy in a mouse cervical cancer model," Vaccine, vol. 28, no. 36, pp. 5794-5802, 2010.

[195] S. Madireddi, R. H. Schabowsky, A. K. Srivastava et al., "SA-41BBL costimulation inhibits conversion of conventional $\mathrm{CD}^{+}$ $\mathrm{T}$ cells into $\mathrm{CD} 4^{+} \mathrm{FoxP}^{+} \mathrm{T}$ regulatory cells by production of IFN- $\gamma$," PLoS ONE, vol. 7, no. 8, Article ID e42459, 2012.

[196] M. J. M. Gooden, G. H. De Bock, N. Leffers, T. Daemen, and H. W. Nijman, "The prognostic influence of tumour-infiltrating lymphocytes in cancer: a systematic review with meta-analysis," British Journal of Cancer, vol. 105, no. 1, pp. 93-103, 2011.

[197] R. K. Sharma, E. S. Yolcu, K. G. Elpek, and H. Shirwan, "Tumor cells engineered to codisplay on their surface 4-1BBL and LIGHT costimulatory proteins as a novel vaccine approach for cancer immunotherapy," Cancer Gene Therapy, vol. 17, no. 10, pp. 730-741, 2010.

[198] K. Youlin, Z. Li, G. Xin et al., "Enhanced function of cytotoxic T lymphocytes induced by dendritic cells modified with truncated PSMA and 4-1BBL," Human Vaccines \& Immunotherapeutics, vol. 9, no. 4, 2013.

[199] K. J. Curran, H. J. Pegram, and R. J. Brentjens, “Chimeric antigen receptors for T cell immunotherapy: current understanding and future directions," The Journal of Gene Medicine, vol. 14, pp. 405415, 2012.

[200] D. L. Porter, B. L. Levine, M. Kalos, A. Bagg, and C. H. June, "Chimeric antigen receptor-modified $\mathrm{T}$ cells in chronic lymphoid leukemia," The New England Journal of Medicine, vol. 365, no. 8, pp. 725-733, 2011.

[201] M. Kalos, B. L. Levine, D. L. Porter et al., "T cells with chimeric antigen receptors have potent antitumor effects and can establish memory in patients with advanced leukemia,"
Science Translational Medicine, vol. 3, no. 95, Article ID 95ra73, 2011.

[202] R. A. Morgan, J. C. Yang, M. Kitano, M. E. Dudley, C. M. Laurencot, and S. A. Rosenberg, "Case report of a serious adverse event following the administration of $\mathrm{t}$ cells transduced with a chimeric antigen receptor recognizing ERBB2," Molecular Therapy, vol. 18, no. 4, pp. 843-851, 2010.

[203] R. Houot, M. J. Goldstein, H. E. Kohrt et al., “Therapeutic effect of CD137 immunomodulation in lymphoma and its enhancement by $\mathrm{T}_{\text {reg }}$ depletion," Blood, vol. 114, no. 16, pp. 34313438, 2009.

[204] A. C. Dowell, K. A. Oldham, R. I. Bhatt, S. P. Lee, and P. F. Searle, "Long-term proliferation of functional human NK cells, with conversion of CD56dim NK cells to a CD56bright phenotype, induced by carcinoma cells co-expressing 4-1BBL and IL-12," Cancer Immunology, Immunotherapy, vol. 61, pp. 615-628, 2012.

[205] D. Müller, K. Frey, and R. E. Kontermann, "A novel antibody4-1BBL fusion protein for targeted costimulation in cancer immunotherapy," The Journal of Immunotherapy, vol. 31, no. 8, pp. 714-722, 2008.

[206] S. Noji, A. Hosoi, K. Takeda et al., "Targeting spatiotemporal expression of CD137 on tumor-infiltrating cytotoxic T lymphocytes as a novel strategy for agonistic antibody therapy," Journal of Immunotherapy, vol. 35, pp. 460-472, 2012.

[207] N. Hornig, V. Kermer, K. Frey et al., "Combination of a bispecific antibody and costimulatory antibody-ligand fusion proteins for targeted cancer immunotherapy," Journal of Immunotherapy, vol. 35, no. 5, pp. 418-429, 2012.

[208] Y. Kuang, L. Zhang, X. Weng, X. Liu, and H. Zhu, "Combination immunotherapy with 4-1BBL and CTLA-4 blockade for the treatment of prostate cancer," Clinical and Developmental Immunology, vol. 2012, Article ID 439235, 6 pages, 2012.

[209] D. J. Paterson, W. A. Jefferies, J. R. Green et al., "Antigens of activated Rat $\mathrm{T}$ lymphocytes including a molecule of 50,000 $\mathrm{M}(\mathrm{r})$ detected only on CD4 positive T blasts," Molecular Immunology, vol. 24, no. 12, pp. 1281-1290, 1987.

[210] M. Croft, "Control of Immunity by the TNFR-related molecule OX40 (CD134)," Annual Review of Immunology, vol. 28, pp. 57$78,2010$.

[211] A. Zingoni, T. Sornasse, B. G. Cocks, Y. Tanaka, A. Santoni, and L. L. Lanier, "Cross-talk between activated human NK cells and $\mathrm{CD}^{+} \mathrm{T}$ cells via OX40-OX40 ligand interactions," The Journal of Immunology, vol. 173, no. 6, pp. 3716-3724, 2004.

[212] P. R. Rogers, J. Song, I. Gramaglia, N. Killeen, and M. Croft, "OX40 promotes Bcl-xL and $\mathrm{Bcl}-2$ expression and is essential for long-term survival of CD4 T cells," Immunity, vol. 15, no. 3, pp. 445-455, 2001.

[213] A. Song, X. Tang, K. M. Harms, and M. Croft, "OX40 and Bcl$\mathrm{xL}$ promote the persistence of CD8 T cells to recall tumorassociated antigen," The Journal of Immunology, vol. 175, no. 6, pp. 3534-3541, 2005.

[214] J. Song, T. So, and M. Croft, "Activation of NF- $\kappa$ B1 by OX40 contributes to antigen-driven T cell expansion and survival," The Journal of Immunology, vol. 180, no. 11, pp. 7240-7248, 2008.

[215] D. E. Evans, R. A. Prell, C. J. Thalhofer, A. A. Hurwitz, and A. D. Weinberg, "Engagement of OX40 enhances antigen-specific $\mathrm{CD}^{+} \mathrm{T}$ cell mobilization/memory development and humoral immunity: comparison of $\alpha \mathrm{OX}-40$ with $\alpha \mathrm{CTLA}-4$," The Journal of Immunology, vol. 167, no. 12, pp. 6804-6811, 2001.

[216] J. R. Maxwell, A. Weinberg, R. A. Prell, and A. T. Vella, "Danger and OX40 receptor signaling synergize to enhance memory $\mathrm{T}$ 
cell survival by inhibiting peripheral deletion," The Journal of Immunology, vol. 164, no. 1, pp. 107-112, 2000.

[217] I. Gramaglia, A. Jember, S. D. Pippig, A. D. Weinberg, N. Killeen, and M. Croft, "The OX40 costimulatory receptor determines the development of CD4 memory by regulating primary clonal expansion," The Journal of Immunology, vol. 165, no. 6, pp. 3043-3050, 2000.

[218] A. R. Weatherill, J. R. Maxwell, C. Takahashi, A. D. Weinberg, and A. T. Vella, "OX40 ligation enhances cell cycle turnover of Ag-activated CD4 T cells in vivo," Cellular Immunology, vol. 209, no. 1, pp. 63-75, 2001.

[219] C. E. Ruby, W. L. Redmond, D. Haley, and A. D. Weinberg, "Anti-OX40 stimulation in vivo enhances $\mathrm{CD}^{+}$memory T cell survival and significantly increases recall responses," European Journal of Immunology, vol. 37, no. 1, pp. 157-166, 2007.

[220] T. Fujita, N. Ukyo, T. Hori, and T. Uchiyama, "Functional characterization of OX40 expressed on human $\mathrm{CD}^{+} \mathrm{T}$ cells," Immunology Letters, vol. 106, no. 1, pp. 27-33, 2006.

[221] I. Gramaglia, A. D. Weinberg, M. Lemon, and M. Croft, "Ox-40 ligand: a potent costimulatory molecule for sustaining primary CD4 T cell responses," The Journal of Immunology, vol. 161, no. 12, pp. 6510-6517, 1998.

[222] J. T. Vetto, S. Lum, A. Morris et al., "Presence of the T-cell activation marker OX-40 on tumor infiltrating lymphocytes and draining lymph node cells from patients with melanoma and head and neck cancers," The American Journal of Surgery, vol. 174 , no. 3, pp. $258-265$, 1997.

[223] A. D. Weinberg, M.-M. Rivera, R. Prell et al., "Engagement of the OX-40 receptor in vivo enhances antitumor immunity," The Journal of Immunology, vol. 164, no. 4, pp. 2160-2169, 2000.

[224] S. Piconese, B. Valzasina, and M. P. Colombo, "OX40 triggering blocks suppression by regulatory $\mathrm{T}$ cells and facilitates tumor rejection," Journal of Experimental Medicine, vol. 205, no. 4, pp. 825-839, 2008.

[225] A. D. Weinberg, N. P. Morris, M. Kovacsovics-Bankowski, W. J. Urba, and B. D. Curti, "Science gone translational: the OX40 agonist story," Immunological Reviews, vol. 244, no. 1, pp. 218231, 2011.

[226] D. Hirschhorn-Cymerman, G. A. Rizzuto, T. Merghoub et al., "OX40 engagement and chemotherapy combination provides potent antitumor immunity with concomitant regulatory $\mathrm{T}$ cell apoptosis," Journal of Experimental Medicine, vol. 206, no. 5, pp. 1103-1116, 2009.

[227] N. Kitamura, S. Murata, T. Ueki et al., "OX40 costimulation can abrogate Foxp $3^{+}$regulatory T cell-mediated suppression of antitumor immunity," International Journal of Cancer, vol. 125, no. 3, pp. 630-638, 2009.

[228] W. L. Redmond, T. Triplett, K. Floyd, and A. D. Weinberg, "Dual anti-OX40/IL-2 therapy augments tumor immunotherapy via IL-2R-mediated regulation of OX40 expression," PLOS ONE, vol. 7, no. 4, Article ID e34467, 2012.

[229] S. Murata, B. H. Ladle, P. S. Kim et al., "OX40 costimulation synergizes with GM-CSF whole-cell vaccination to overcome established $\mathrm{CD}^{+} \mathrm{T}$ cell tolerance to an endogenous tumor antigen," The Journal of Immunology, vol. 176, no. 2, pp. 974-983, 2006.

[230] N. Müller, A. Wyzgol, S. Münkel, K. Pfizenmaier, and H. Wajant, "Activity of soluble OX40 ligand is enhanced by oligomerization and cell surface immobilization," FEBS Journal, vol. 275, no. 9, pp. 2296-2304, 2008.

[231] P. A. Ascierto, M. Capone, W. J. Urba et al., “The additional facet of immunoscore: immunoprofiling as a possible predictive tool for cancer treatment," Journal of Translational Medicine, vol. 11, p. 54, 2013.

[232] O. Hamid, H. Schmidt, A. Nissan et al., "A prospective phase II trial exploring the association between tumor microenvironment biomarkers and clinical activity of ipilimumab in advanced melanoma," Journal of Translational Medicine, vol. 9, no. 1, article 204, 2011. 


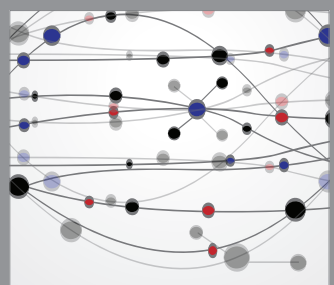

The Scientific World Journal
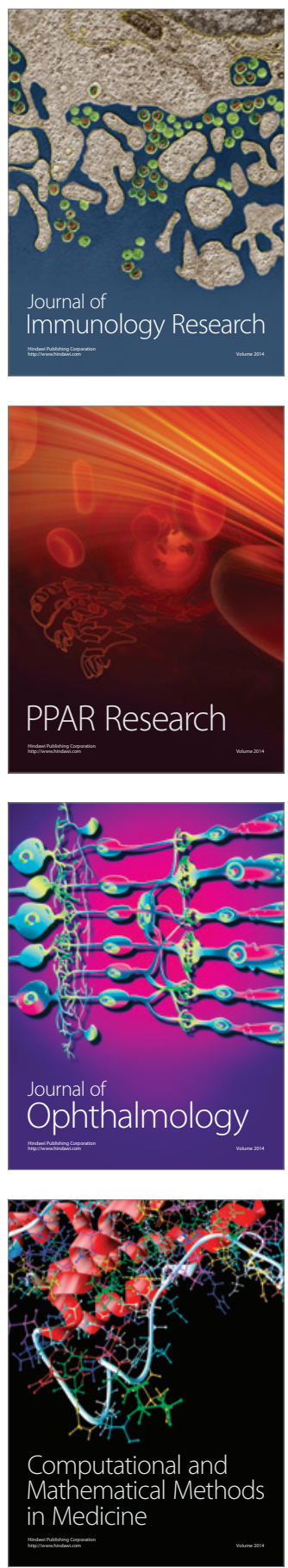

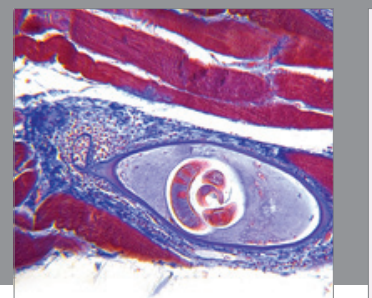

Gastroenterology

Research and Practice
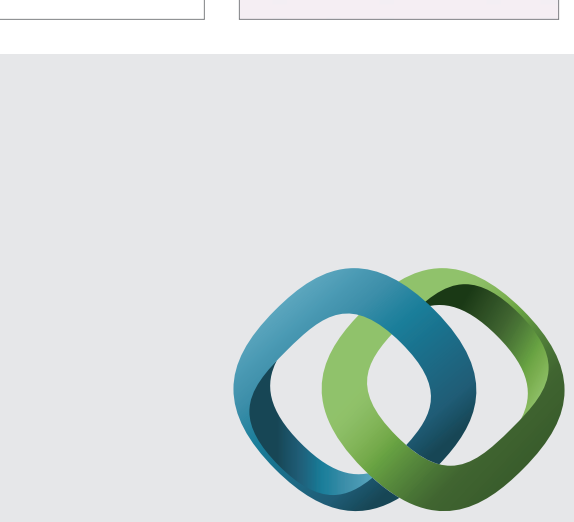

\section{Hindawi}

Submit your manuscripts at

http://www.hindawi.com
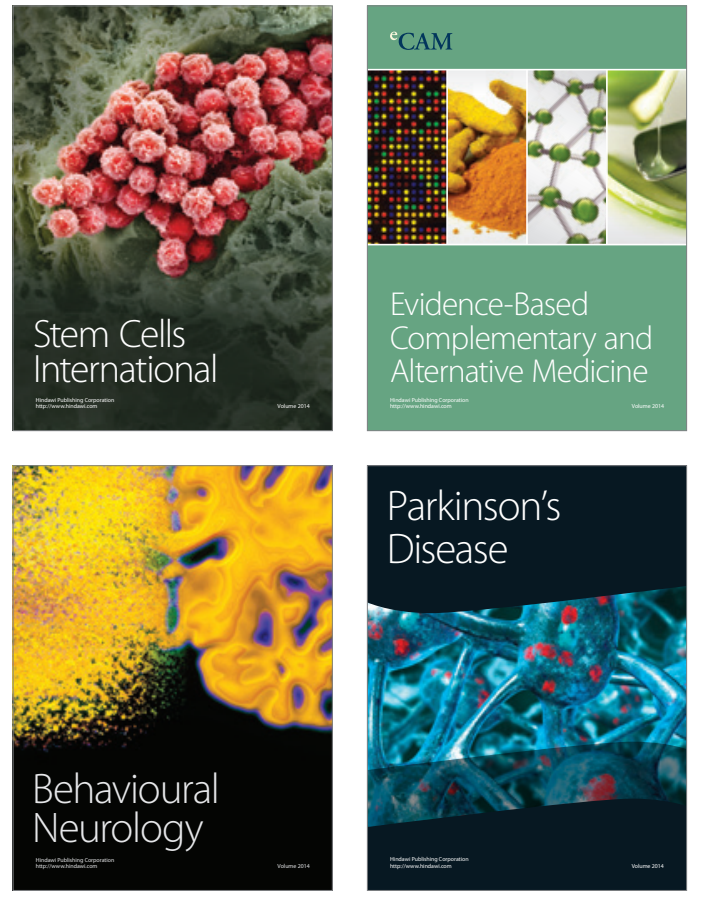
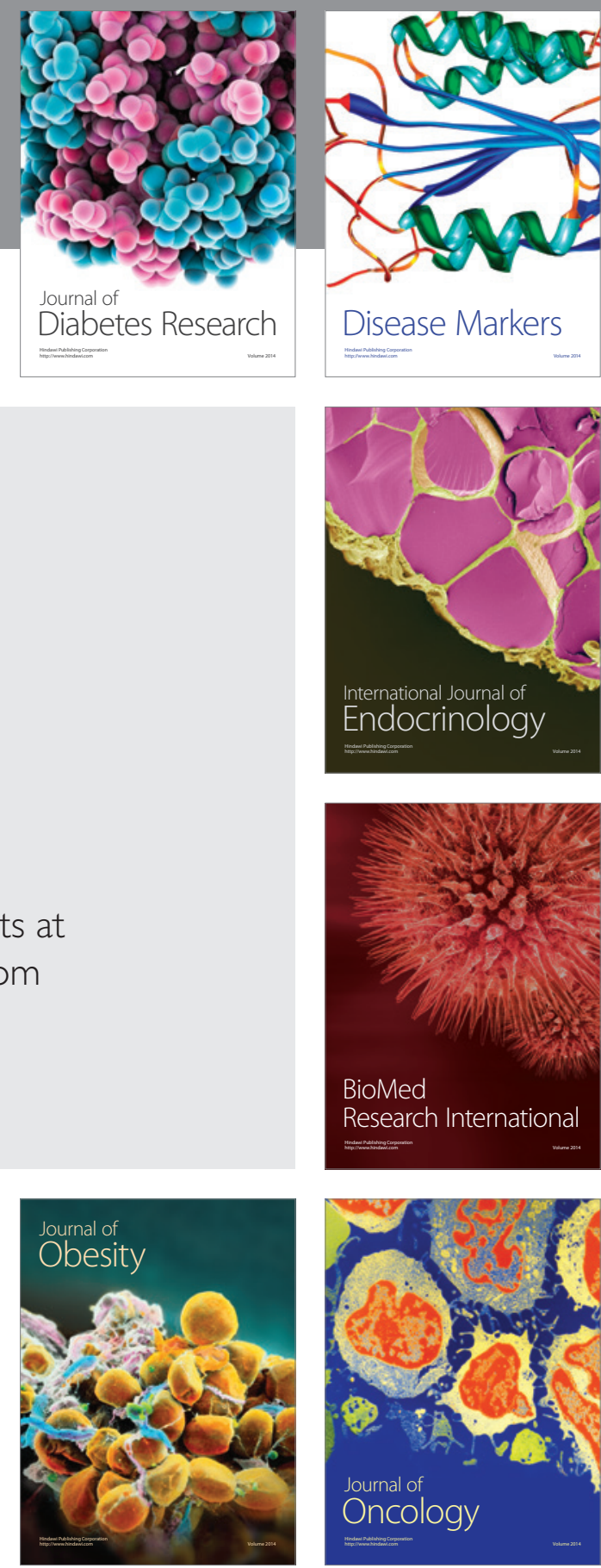

Disease Markers
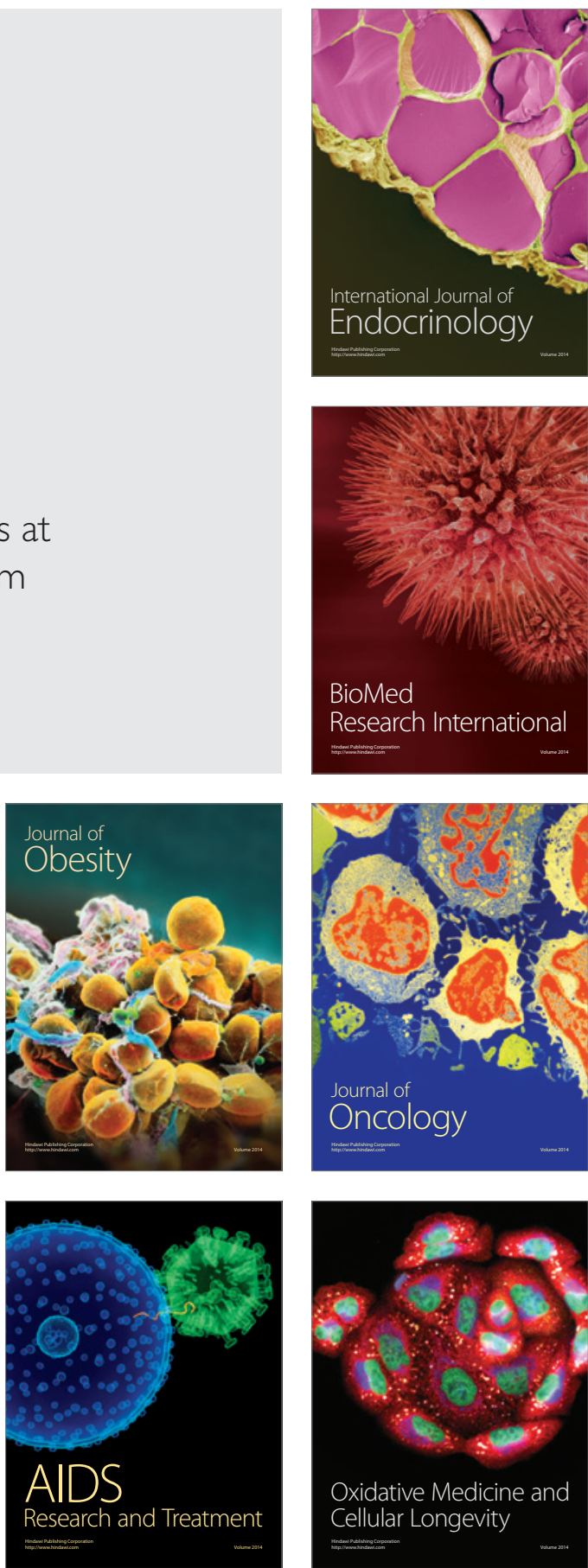